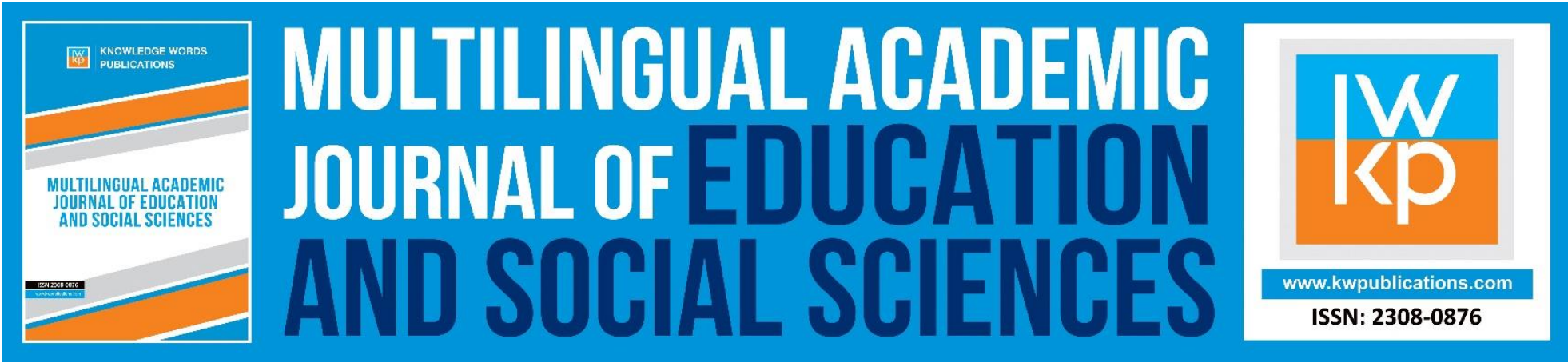

\title{
Young People in Crisis: Constructions of Brain Drain in the Discourse of Greek Neomigrants and the Media
}

\author{
Maria (Mariza) Georgalou, Theodora P. Saltidou \& Eleni Griva
}

To Link this Article: http://dx.doi.org/10.46886/MAJESS/v7-i1/5942

DOI:10.46886/MAJESS/v7-i1/5942

Received: 03 June 2019, Revised: 17 July 2019, Accepted: 01 August 2019

Published Online: 22 August 2019

In-Text Citation: (Georgalou, Saltidou, \& Griva, 2019)

To Cite this Article: Georgalou, M., Saltidou, T. P., \& Griva, E. (2019). Young people in crisis: Constructions of Brain Drain in the discourse of Greek neomigrants and the Media. Multilingual Academic Journal of Education and Social Sciences, 7(1), 77-96. (in Greek)

Copyright: (C) The Authors 2019

Published by Knowledge Words Publications (www.kwpublications.com)

This article is published under the Creative Commons Attribution (CC BY 4.0) license. Anyone may reproduce, distribute, translate and create derivative works of this article (for both commercial and non-commercial purposes), subject to full attribution to the original publication and authors. The full terms of this license may be seen

at: http://creativecommons.org/licences/by/4.0/legalcode

Vol. 7, No. 1, 2019, Pg. 77 - 96

https://kwpublications.com/journals/journaldetail/MAJESS

JOURNAL HOMEPAGE

Full Terms \& Conditions of access and use can be found at https://kwpublications.com/pages/detail/publication-ethics 


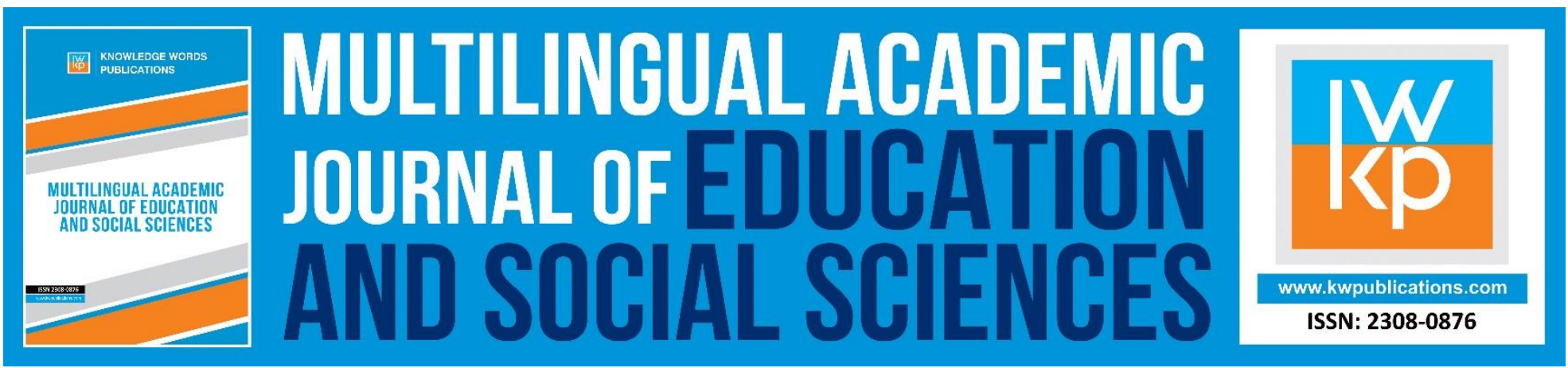

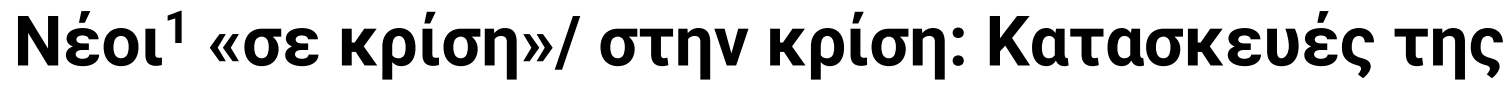 $\varepsilon \pi$ I

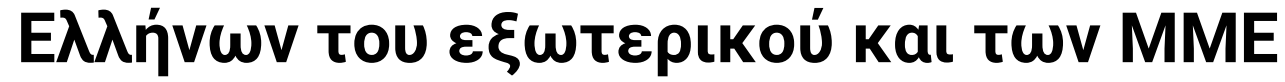

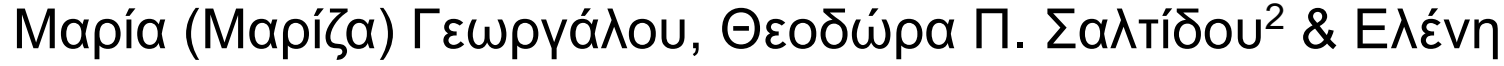 \\ Грі́ßa
}

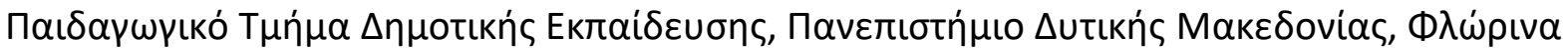

\begin{abstract}
Since the onset of the Greek crisis, thousands of - mainly young - highly educated and skilled Greeks have chosen or/and have been forced to migrate in search of better career prospects and living standards. This neomigratory wave is broadly known with the neologism 'brain drain'. The present study focuses on the ways in which selected Greek neomigrants present in their discourse their incentives to leave Greece as well as the ways in which they use social media projecting specific migrant identities (micro-level). It also examines the ways in which brain drain is discussed and constructed as discourse in infotainment media (macro-level). Drawing on insights from discourse-centred online ethnography, the Foucauldian perspective on discourse and Systemic Functional Linguistics, we present and discuss ethnographic data (interviews and social media posts) from selected Greek neomigrants settled in the UK and Germany, and media data from well-known infotainment websites. Our analysis demonstrates that the micro- and the macro-level are intertwined. Moreover, it indicates that the construction of brain drain amalgamates features of economic migration with features of lifestyle migration. In so doing, it sheds light on the broader socio-cultural and psychological impact of brain drain on neomigrants themselves and the Greek society.
\end{abstract}

Keywords: Greek Brain Drain, Migrant Discourse, Social Media, Infotainment Media, Discourse Analysis.

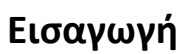

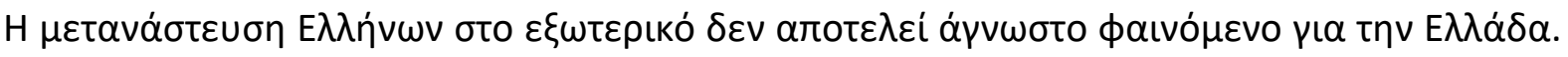

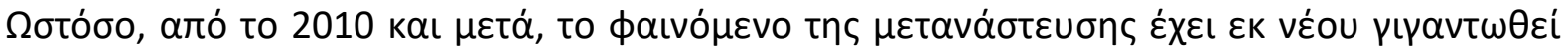

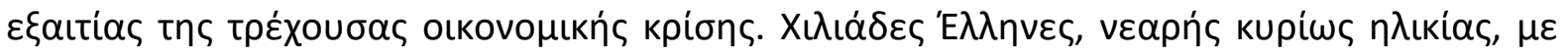

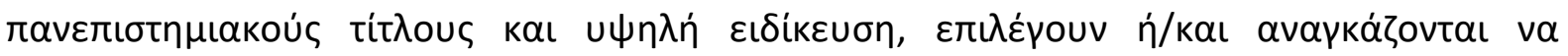

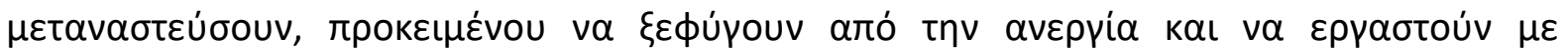

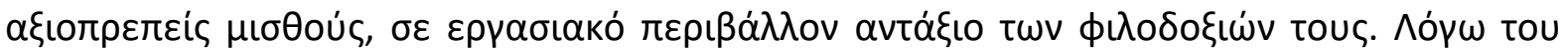

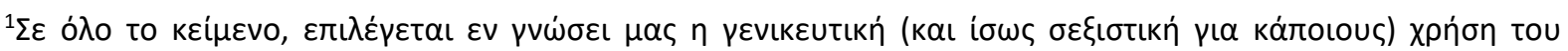

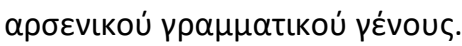

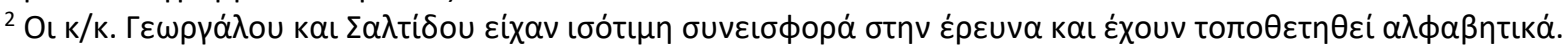




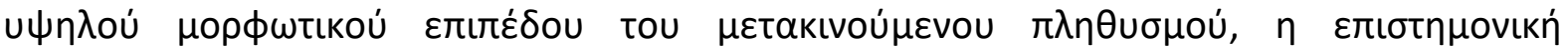

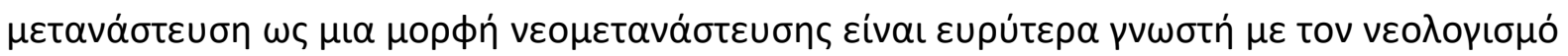

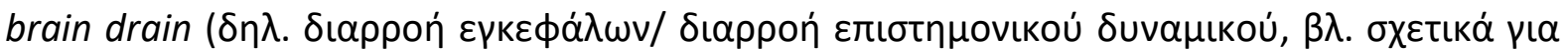

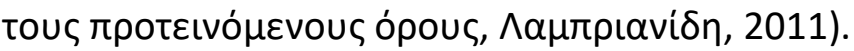

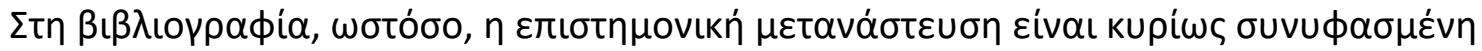

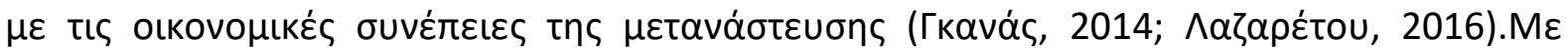

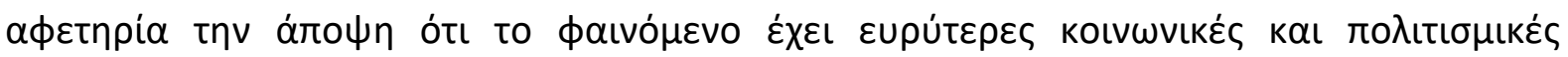

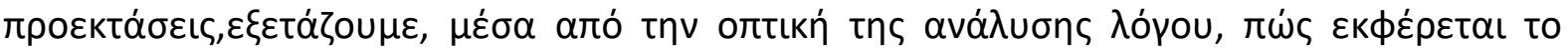

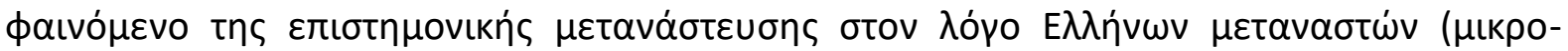

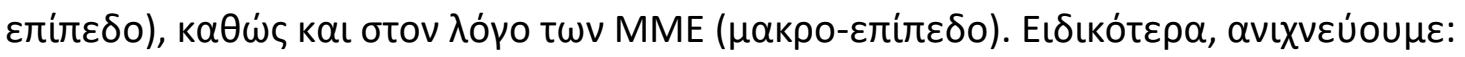

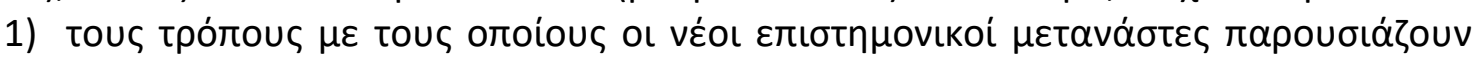

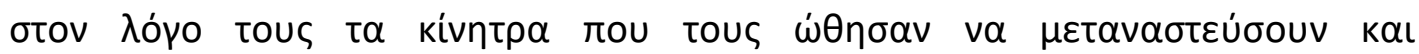

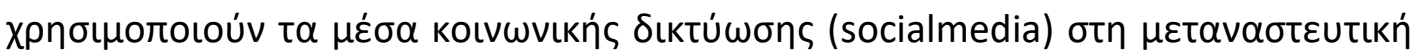

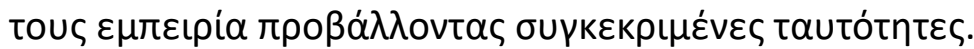

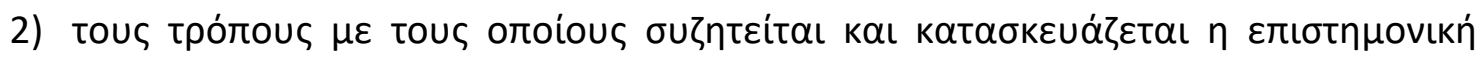

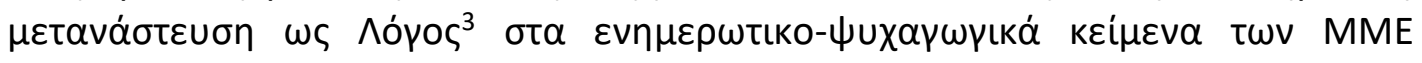
(infotainment media).

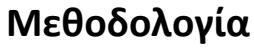

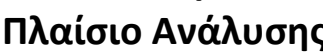

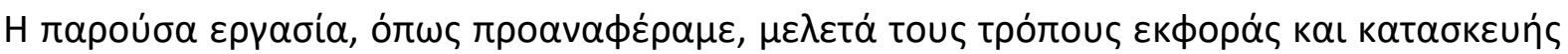

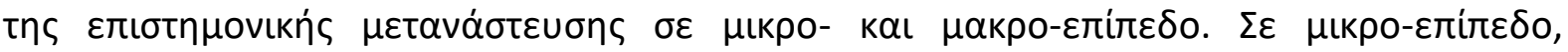

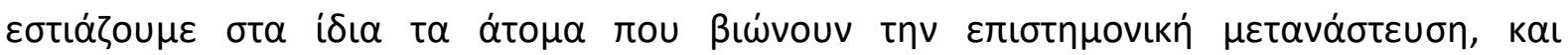

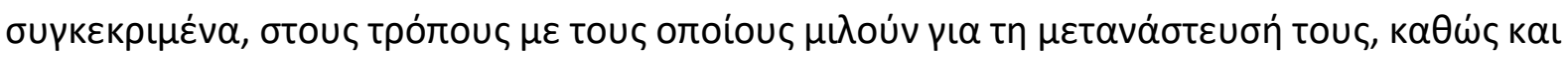

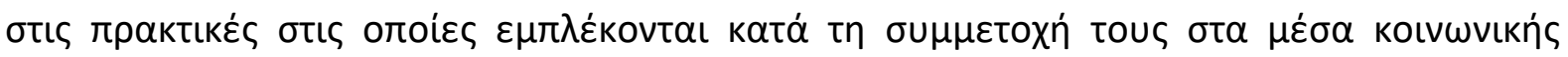

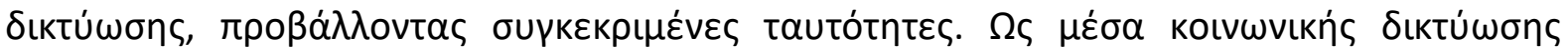

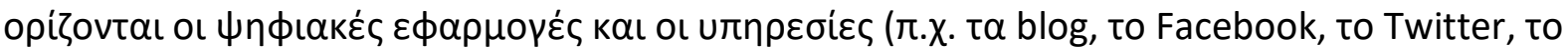

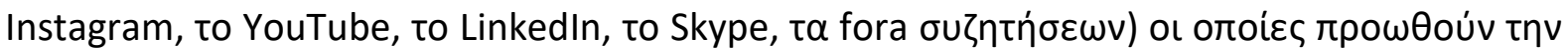

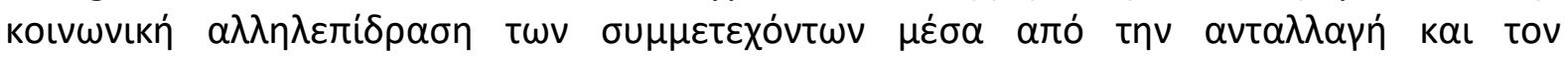

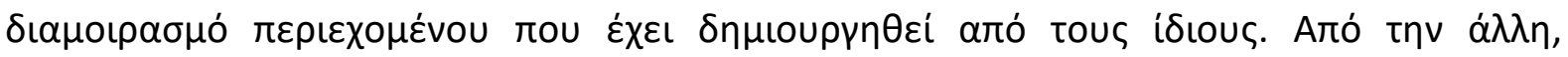

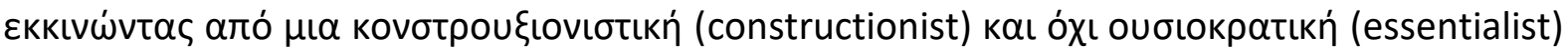

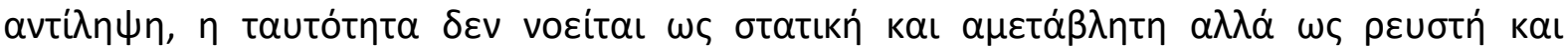

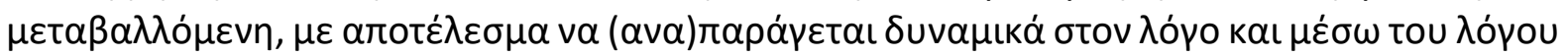

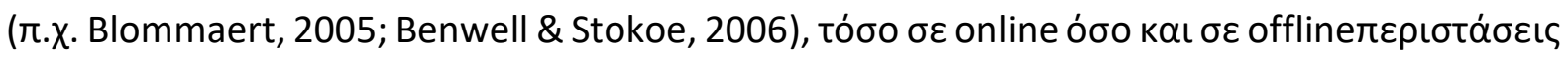

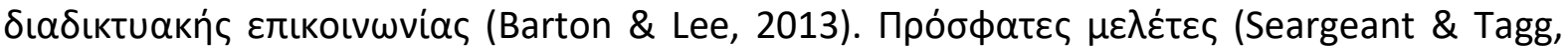

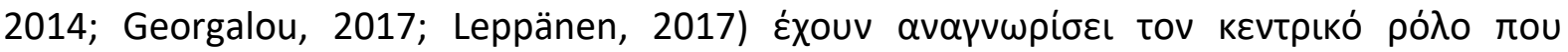

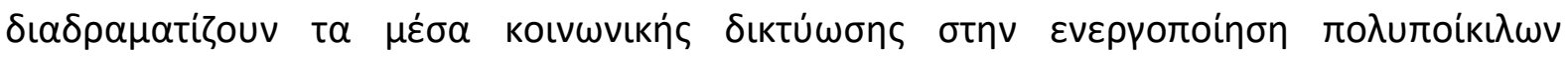

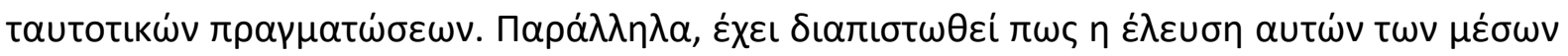

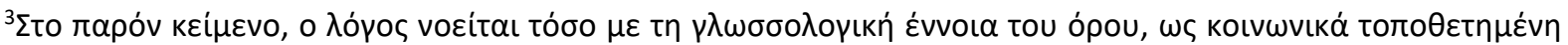

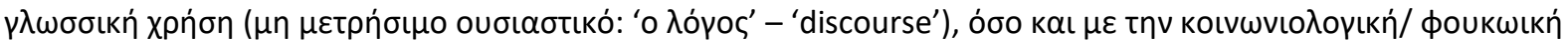

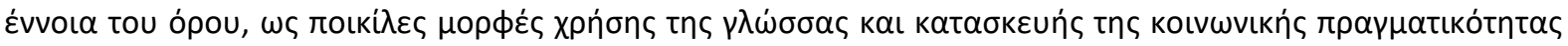

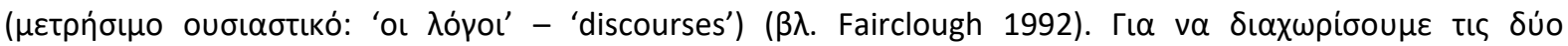

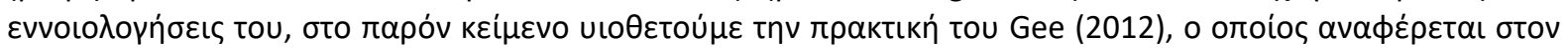

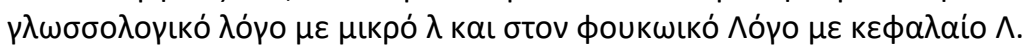




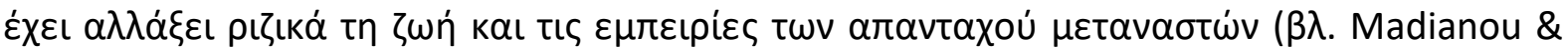
Miller, 2012).

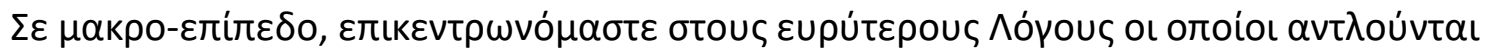

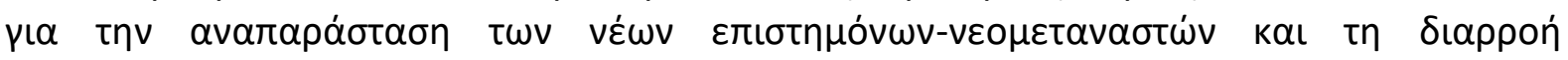

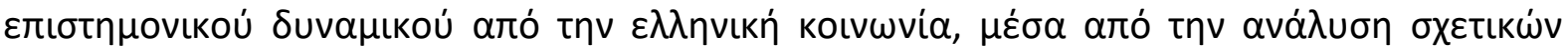

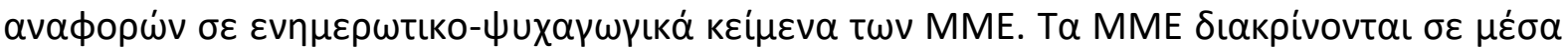

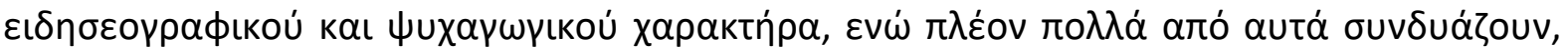

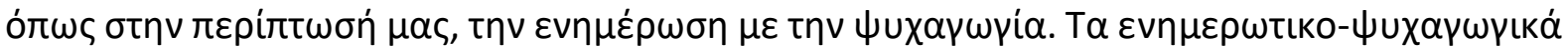

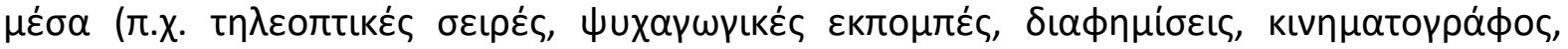

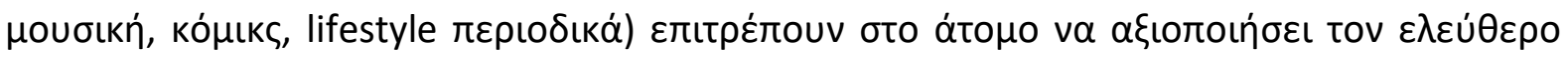

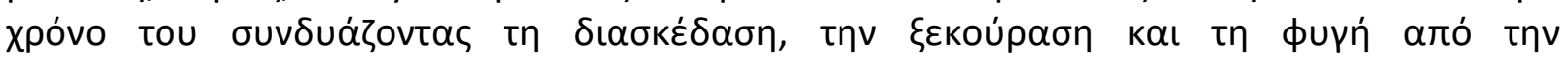

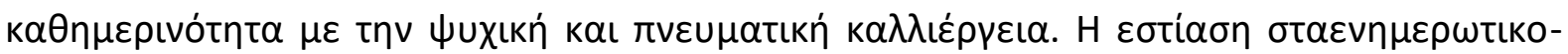

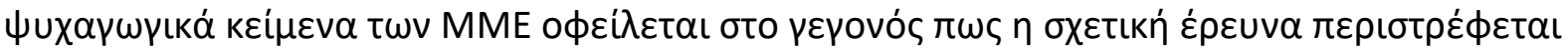

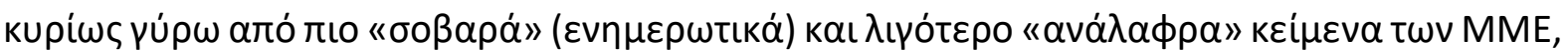

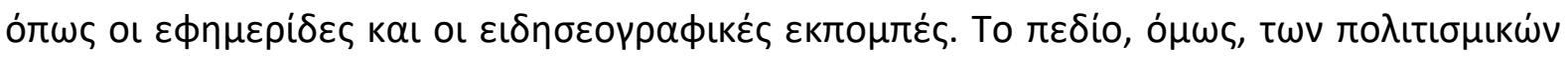

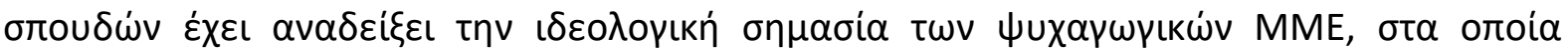

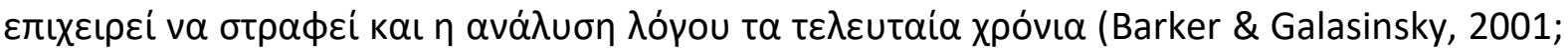

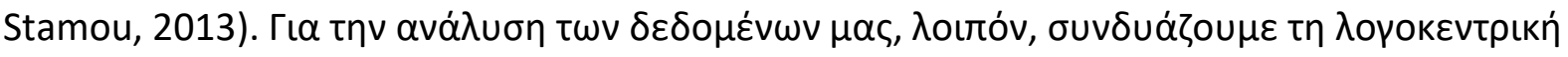

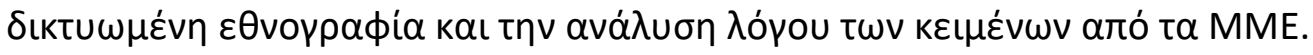

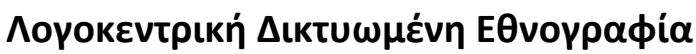

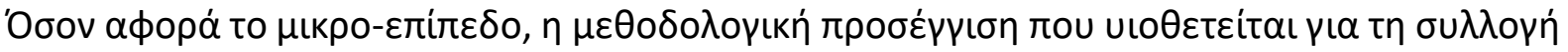

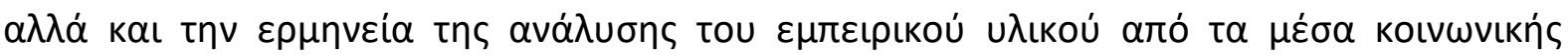

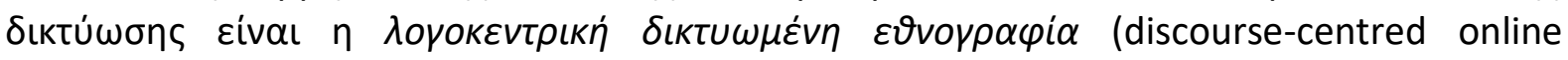

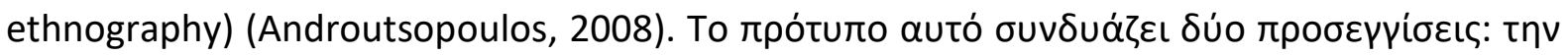

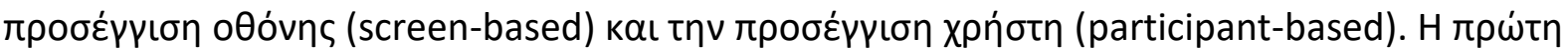

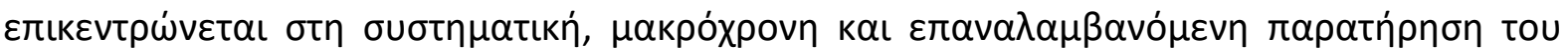

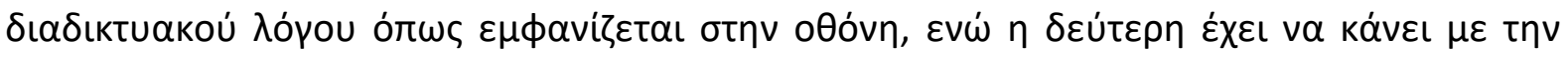

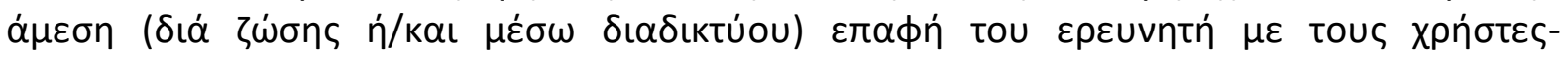

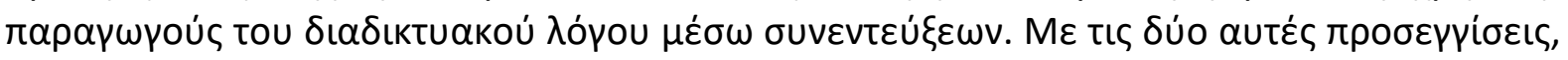

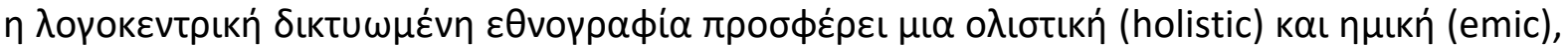

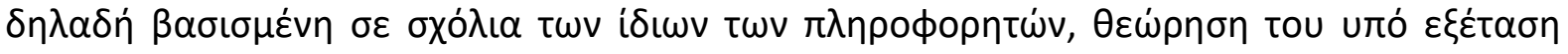
$\theta \varepsilon \dot{\mu} \mu$ тос.

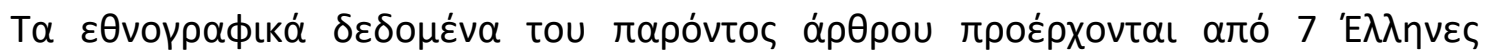

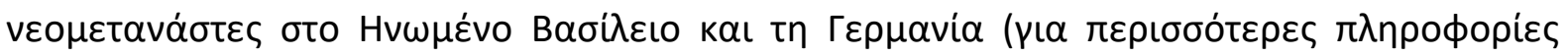

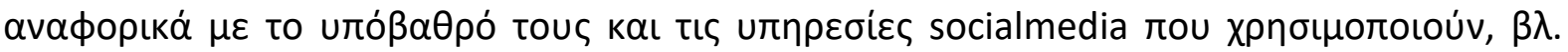

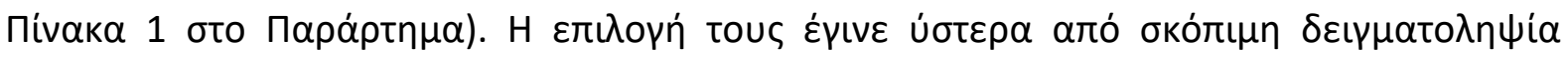

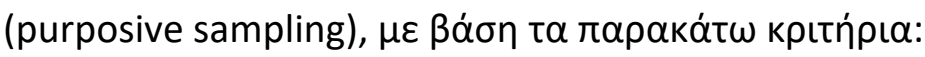

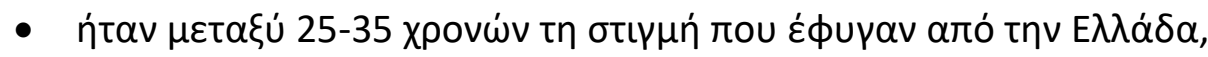

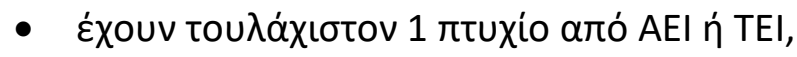

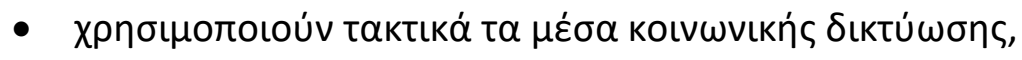

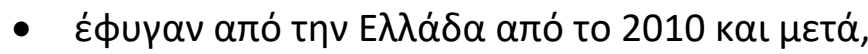

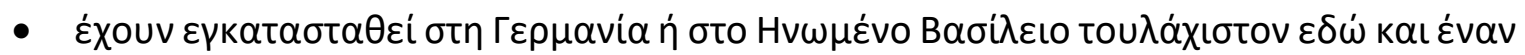

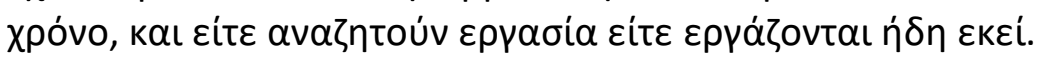

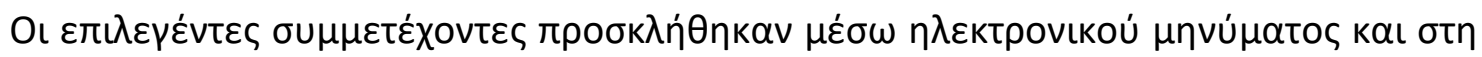

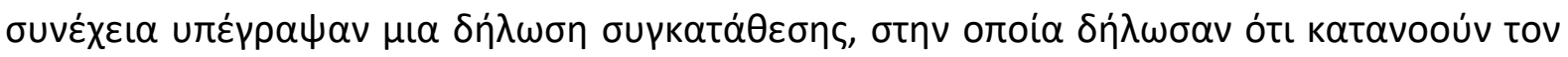

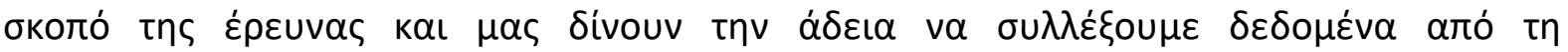




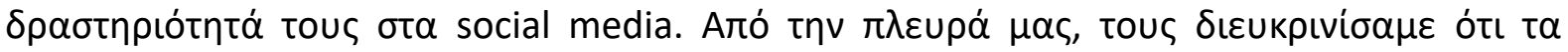

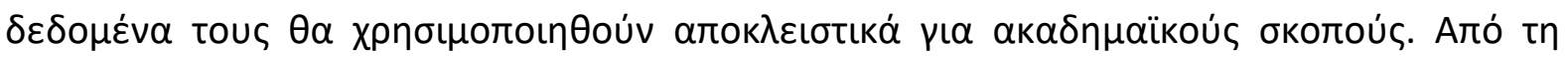

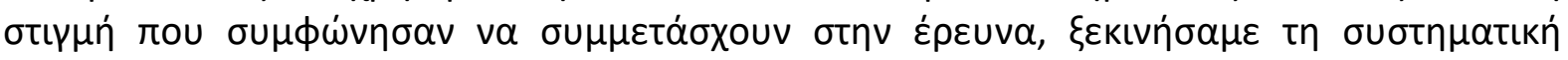

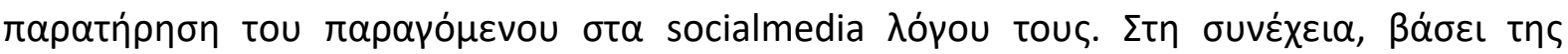

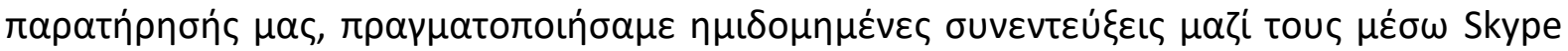

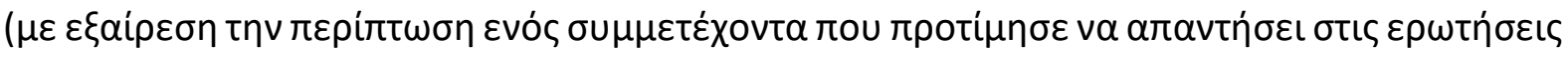

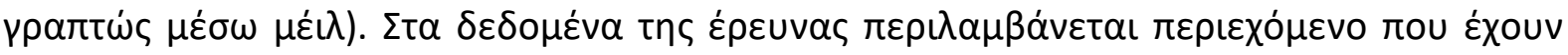

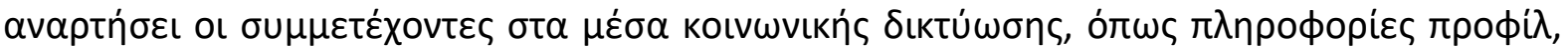

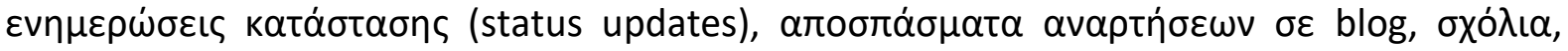

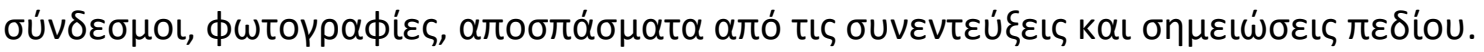

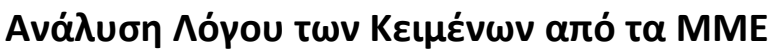

Гı

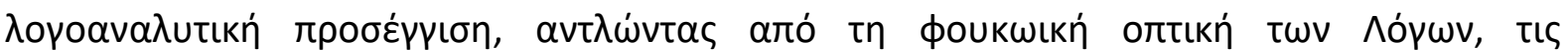

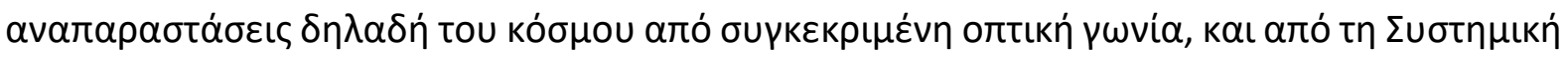

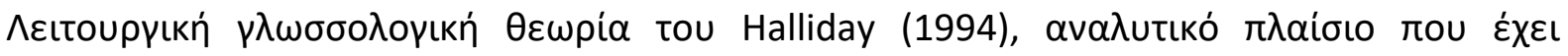

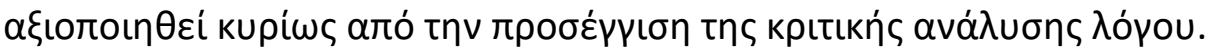

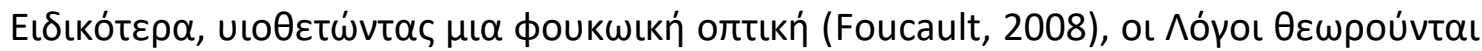

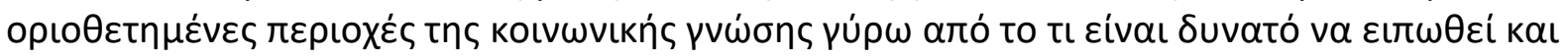

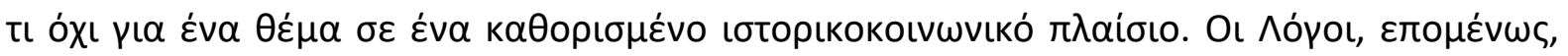

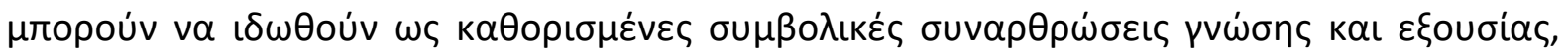

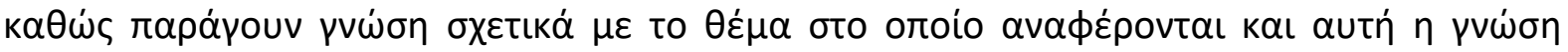

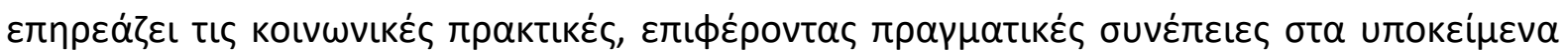

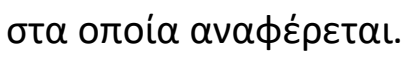

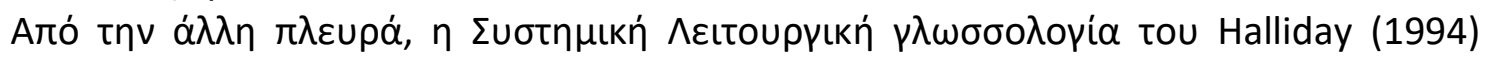

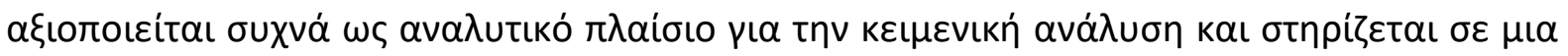

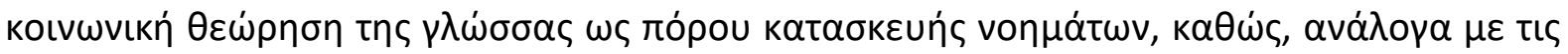

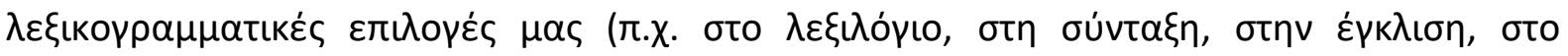

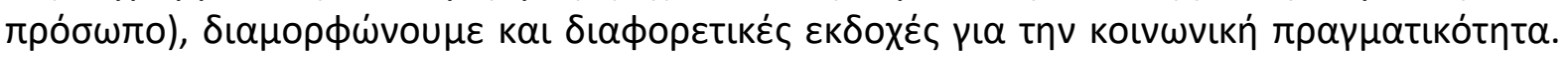

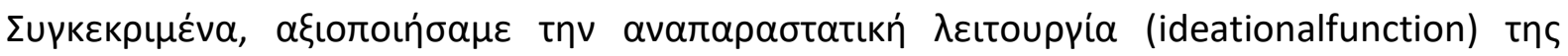

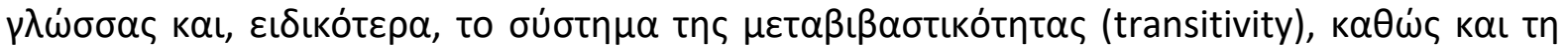

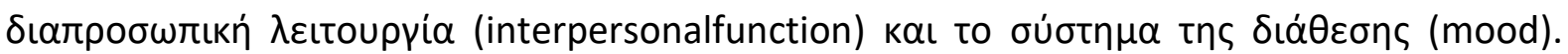

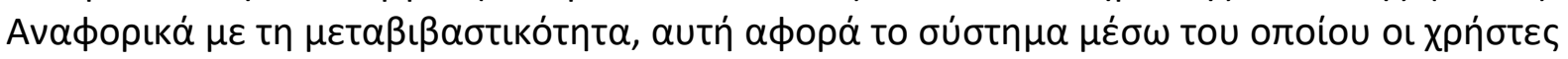

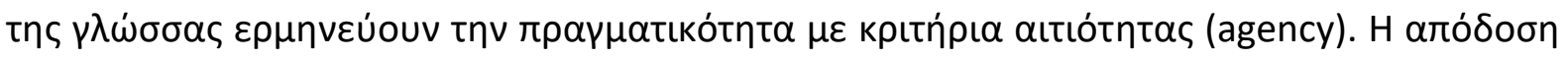

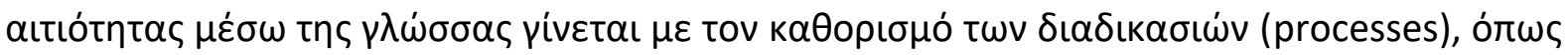

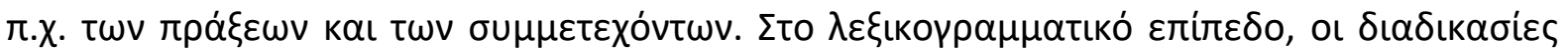

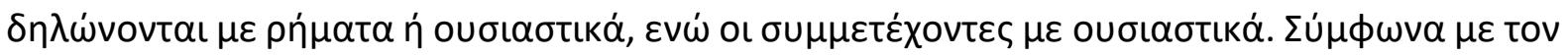

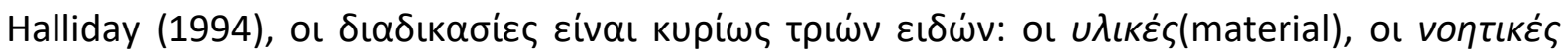

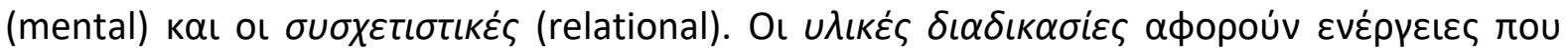

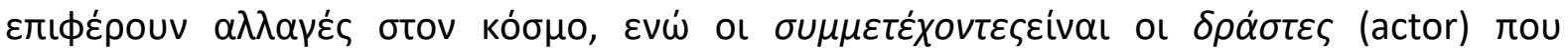

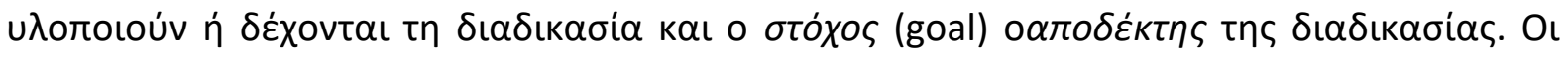

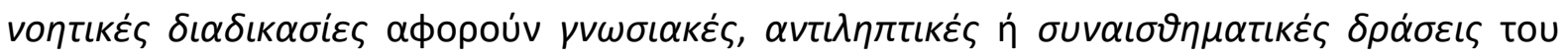

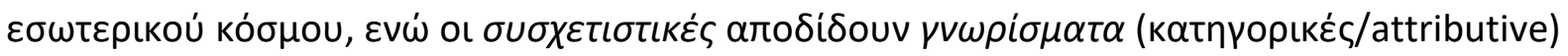

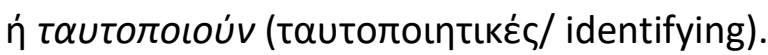

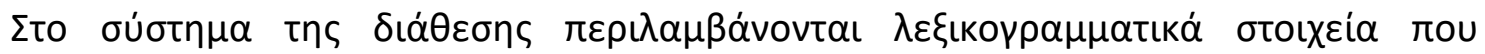

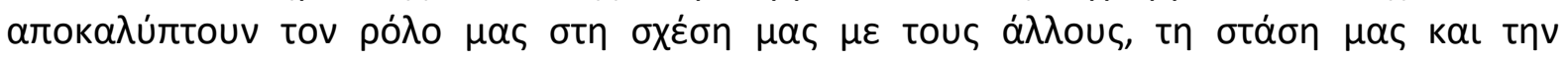

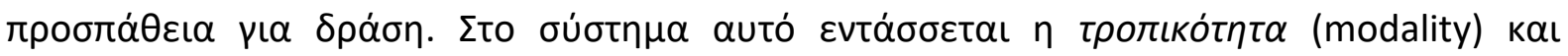




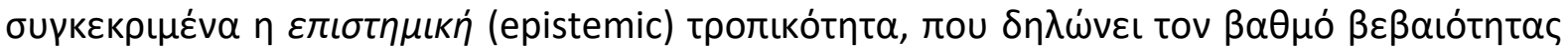

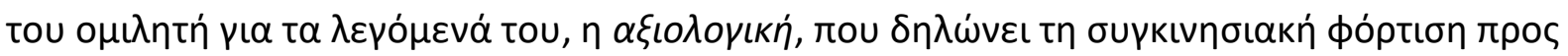

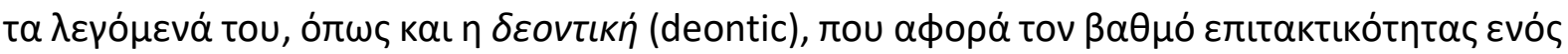

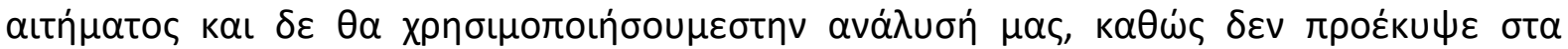

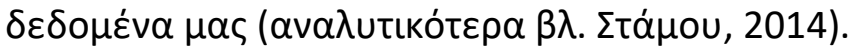

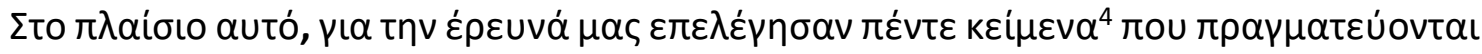

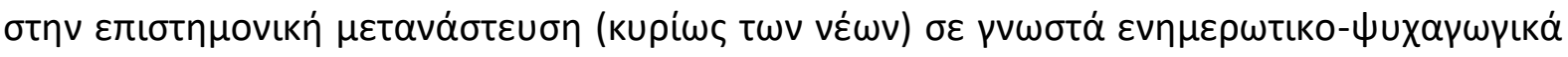

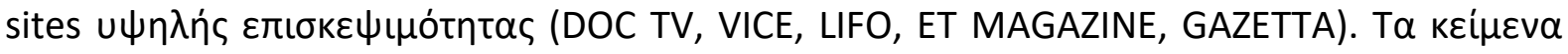

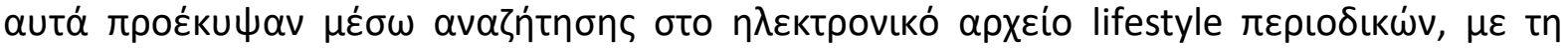

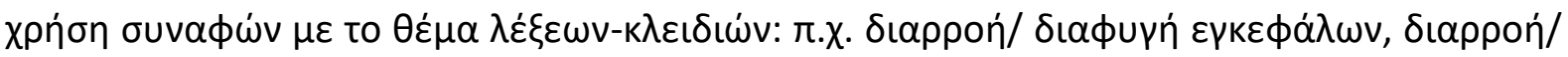

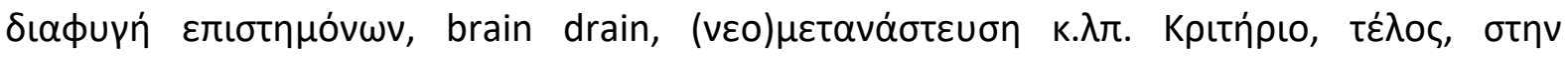

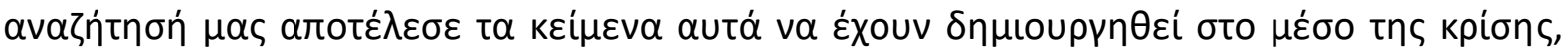

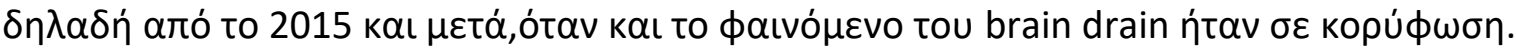

\section{Avó̀uon}

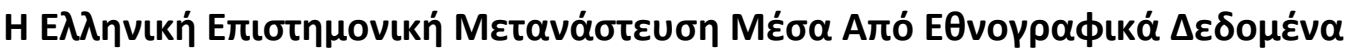

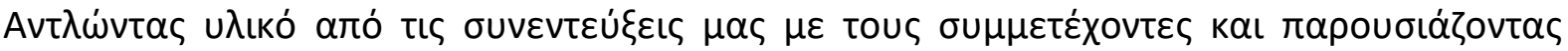

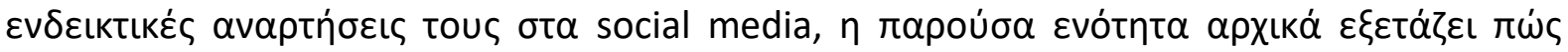

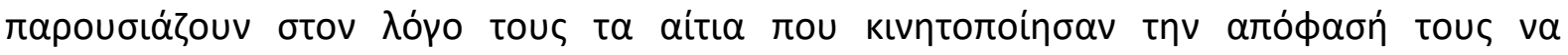

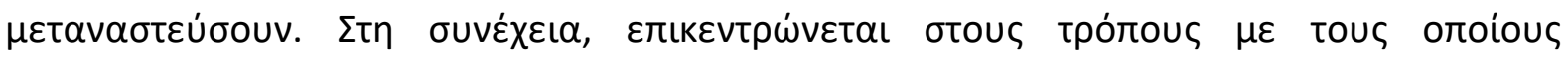

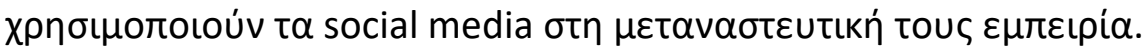

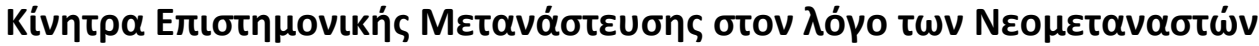

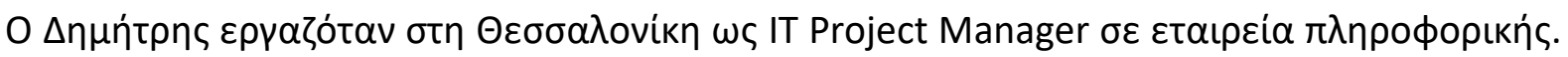

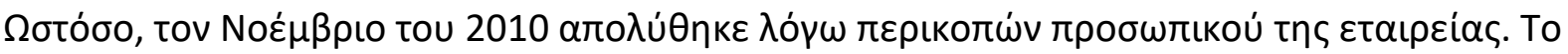

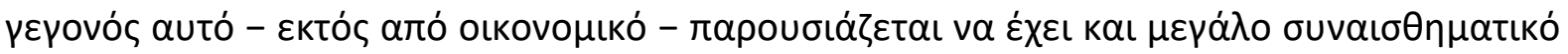

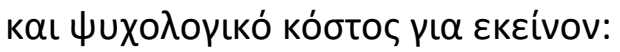

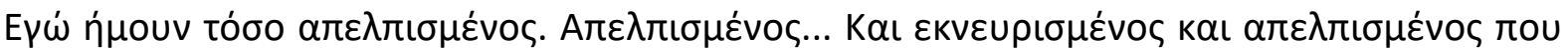

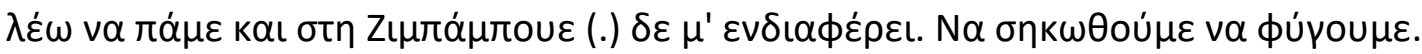

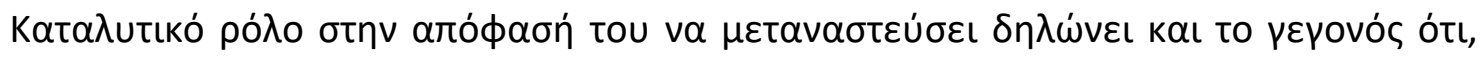

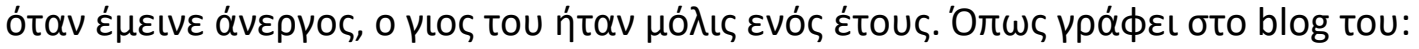

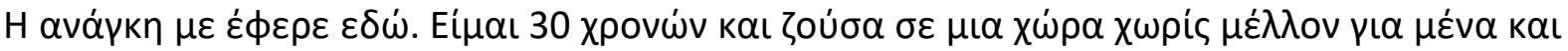

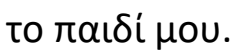

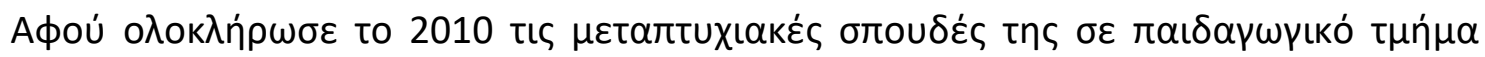

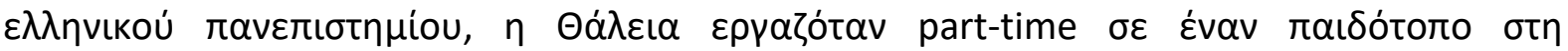

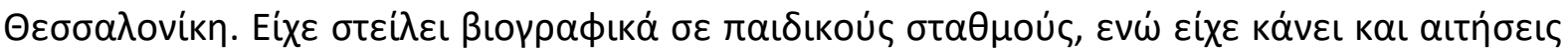

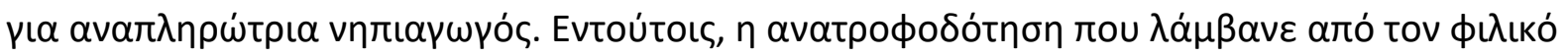

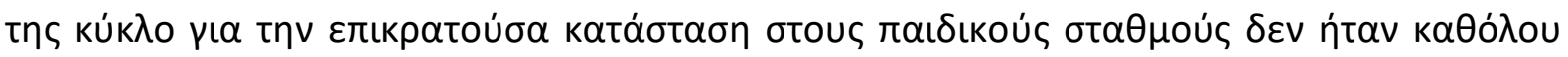

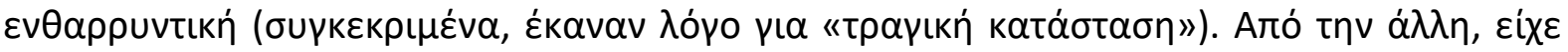

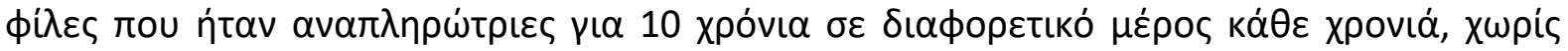

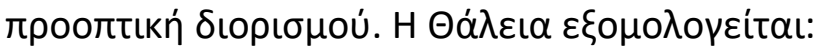

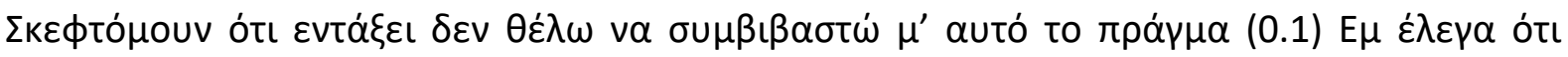

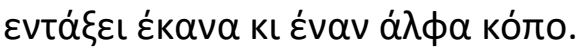

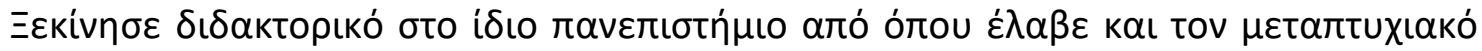

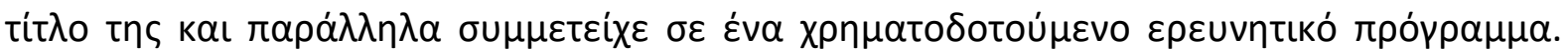

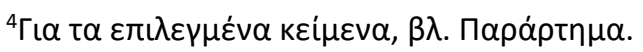




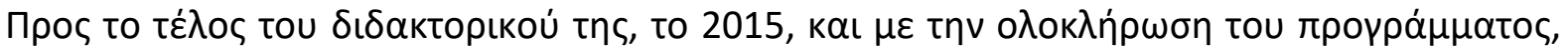

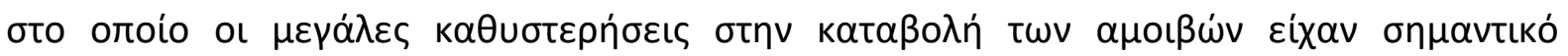

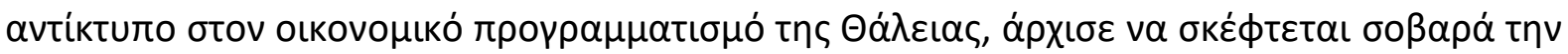

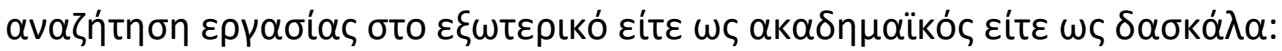

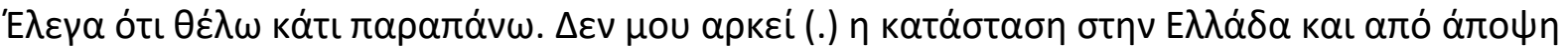

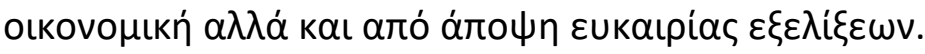

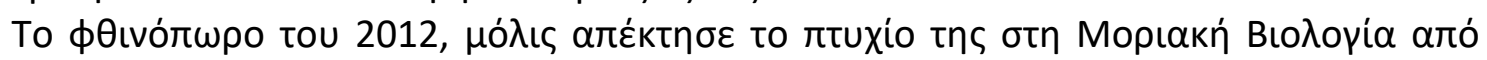

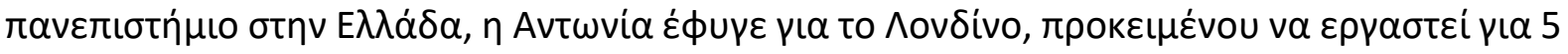

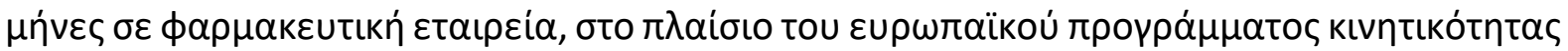

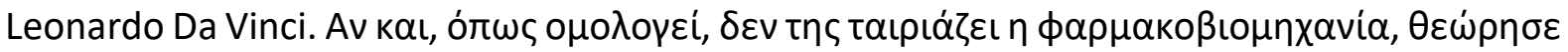

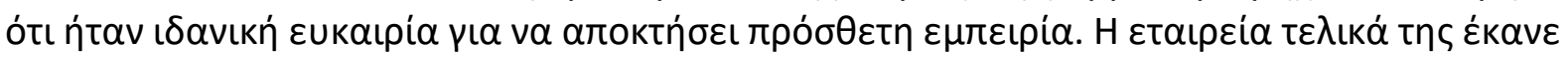

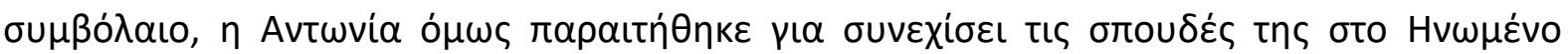

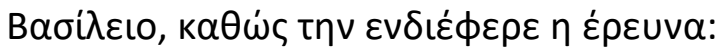

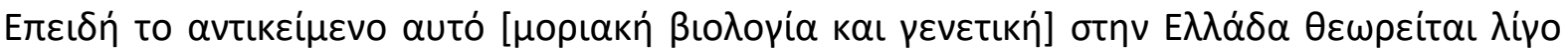

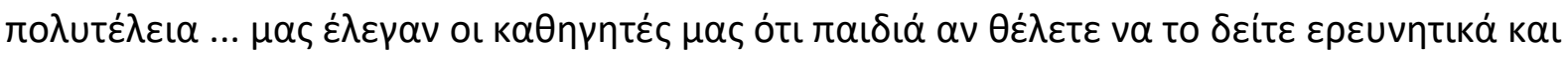

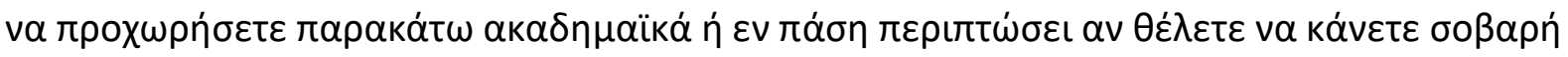

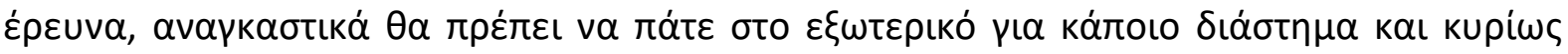

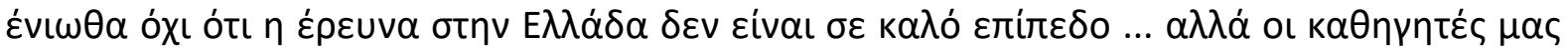

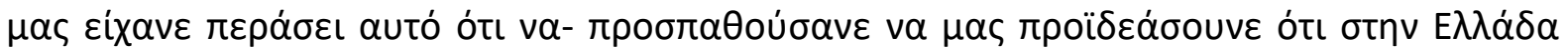

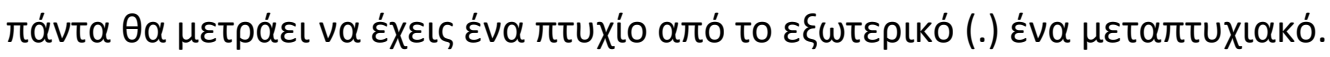

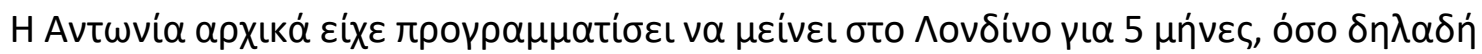

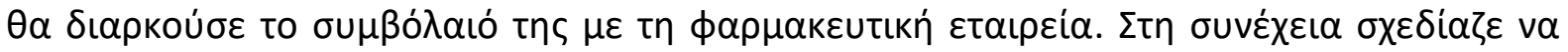

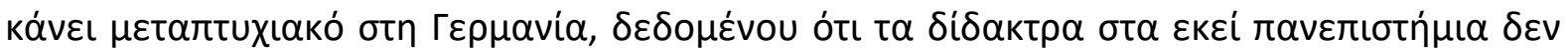

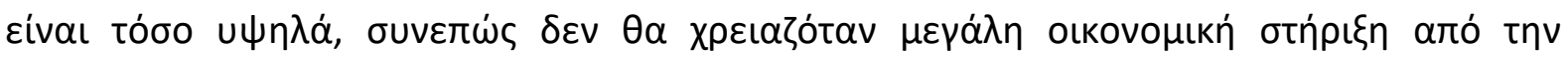

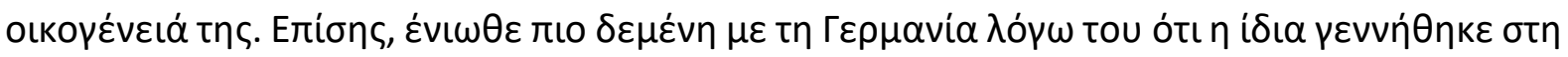

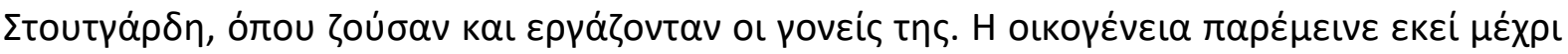

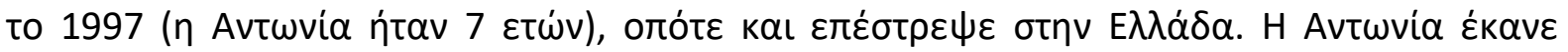

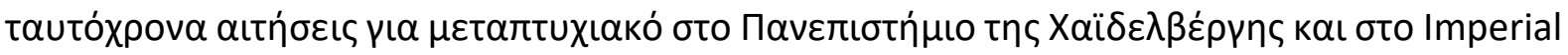

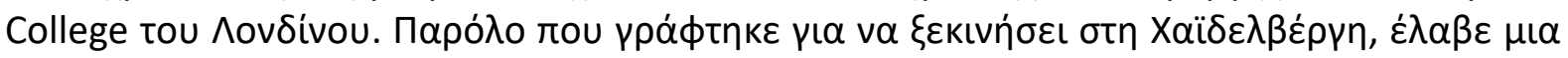

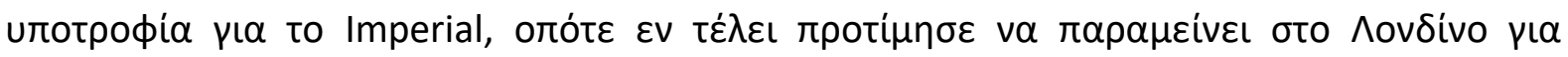

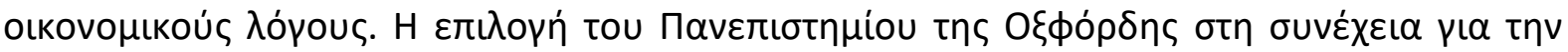

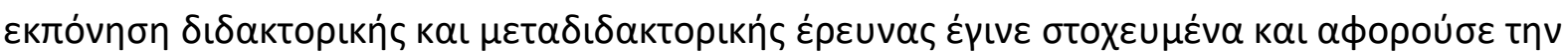

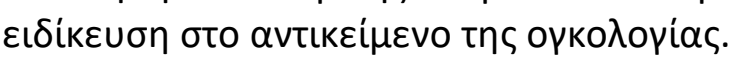

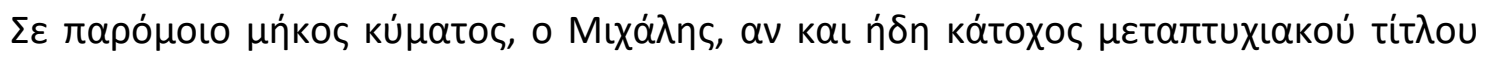

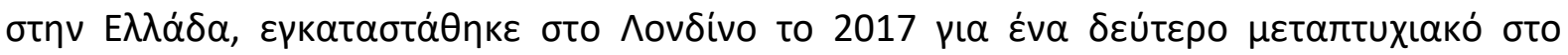

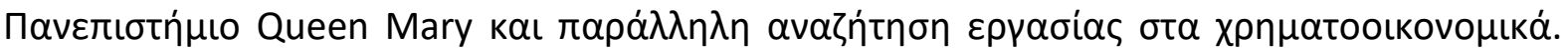

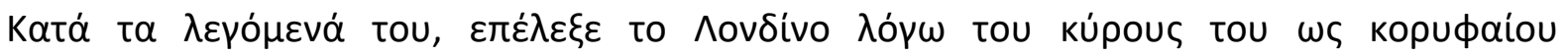

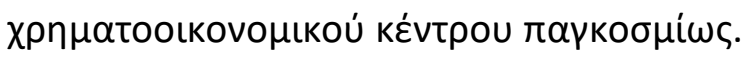

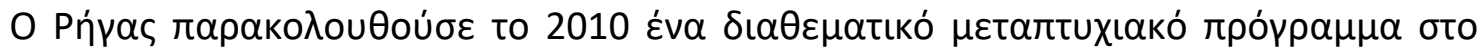

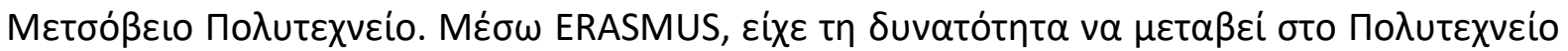

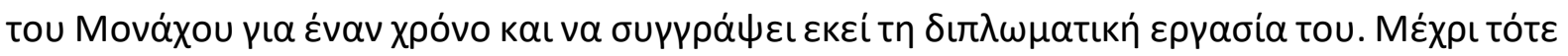

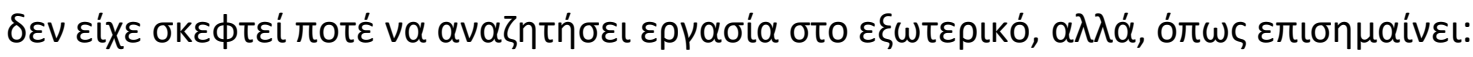

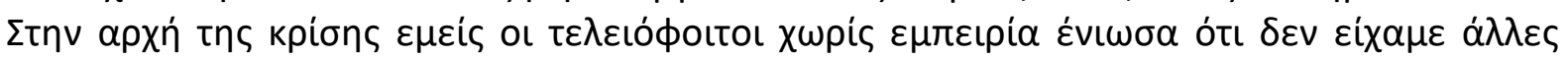
$\varepsilon \pi \iota \lambda о \gamma \varepsilon \dot{\varsigma}$.

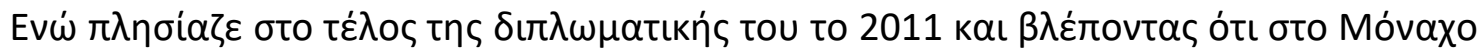

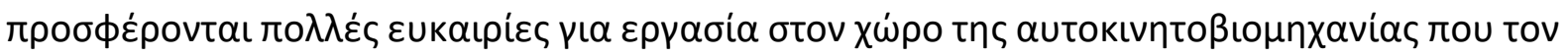

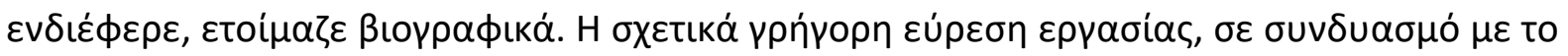




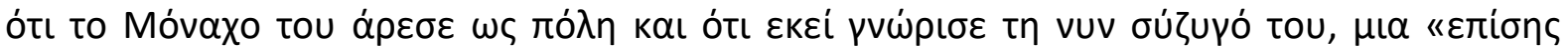

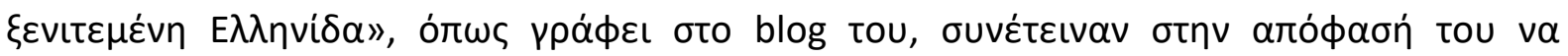

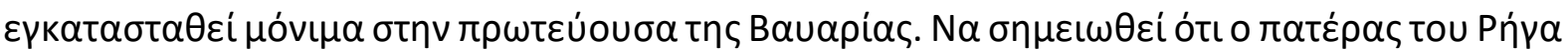

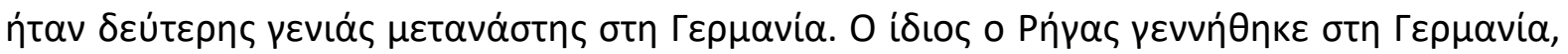

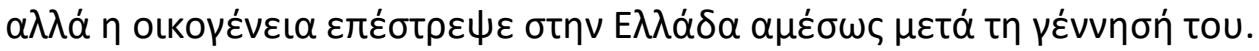

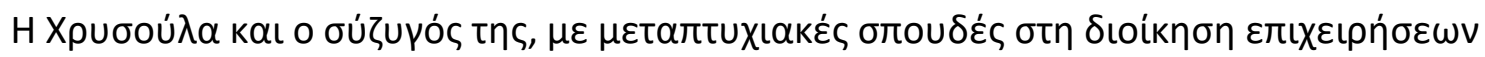

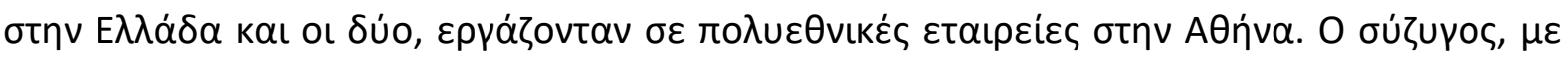

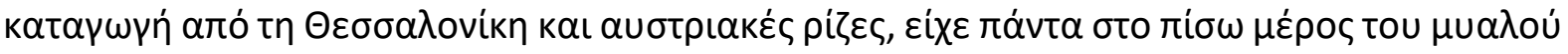

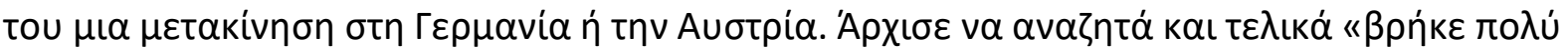

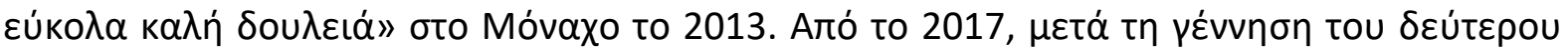

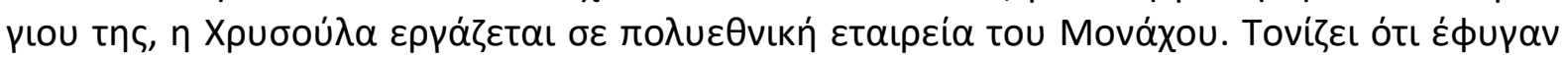

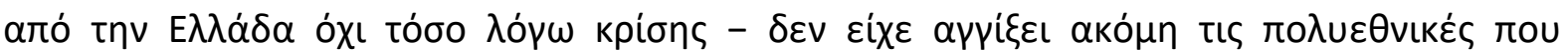

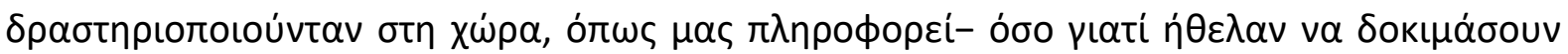

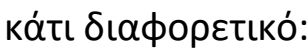

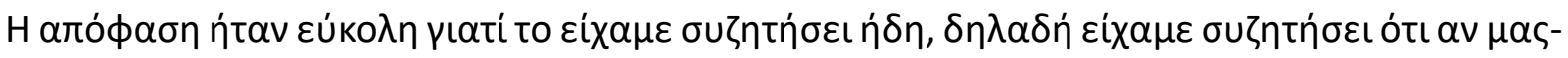

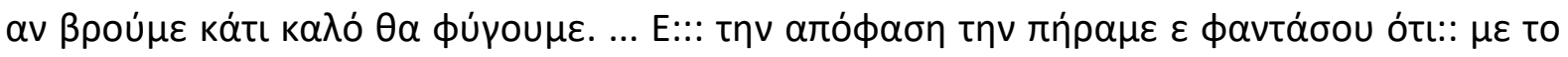

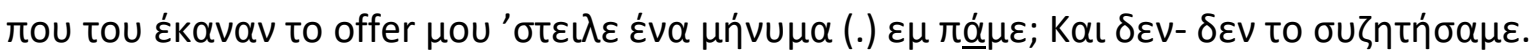

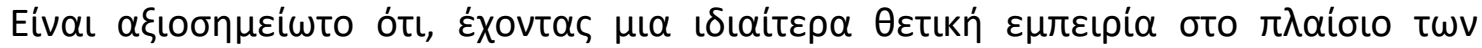

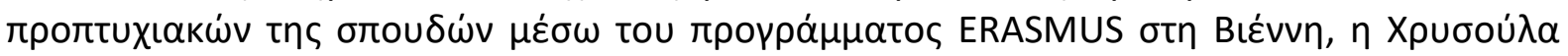

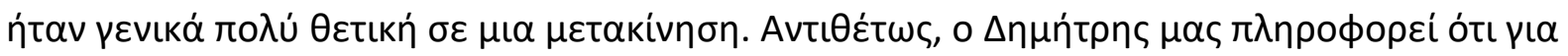

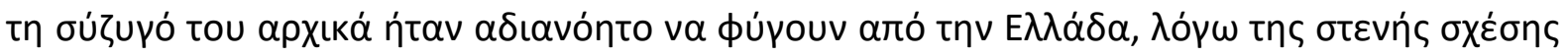

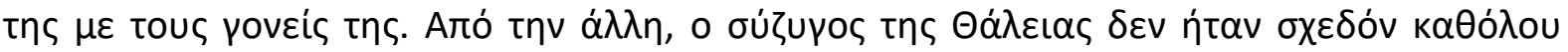

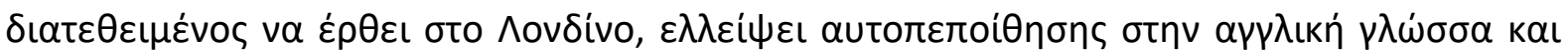

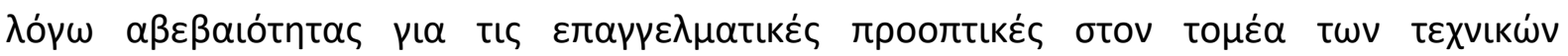

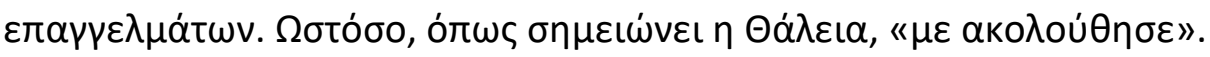

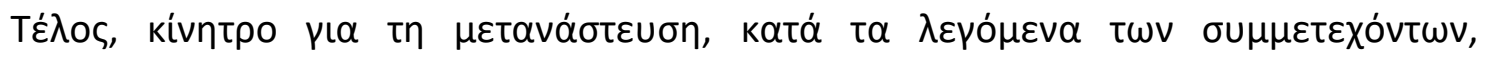

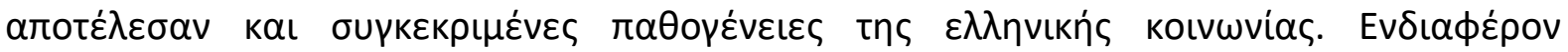

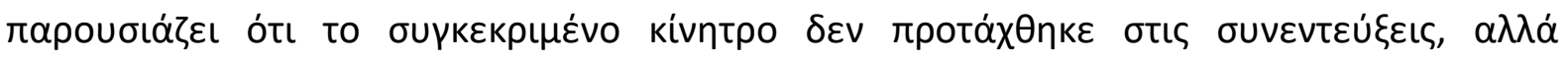

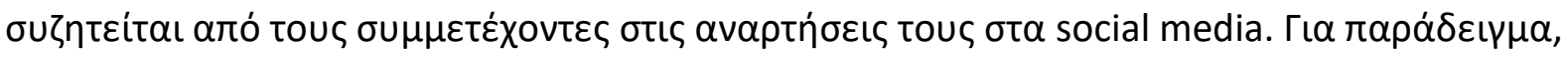

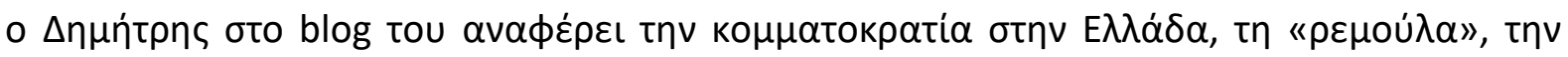

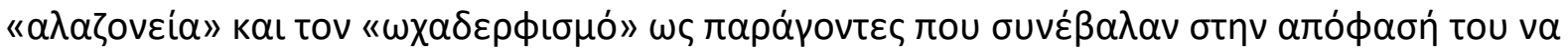

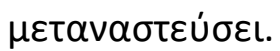

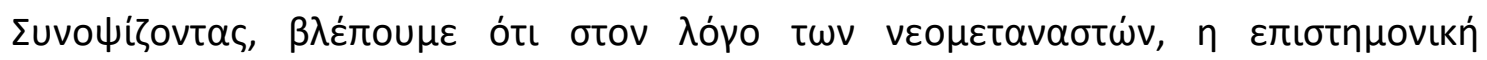

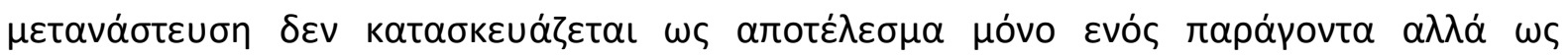

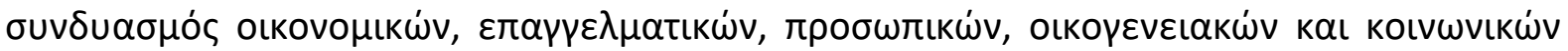

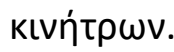

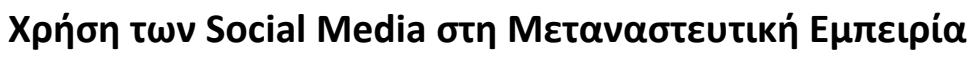

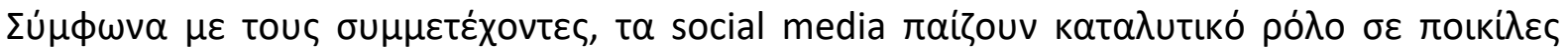

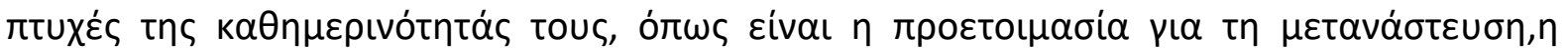

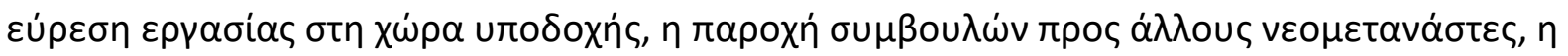

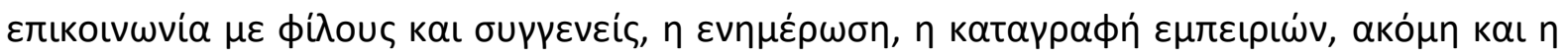

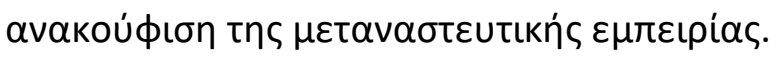




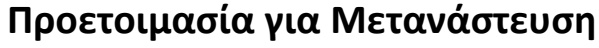

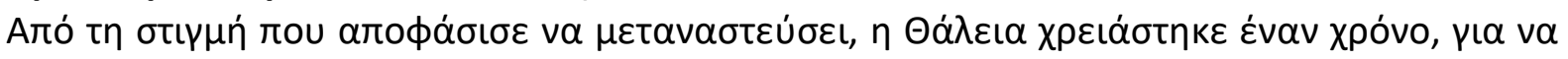

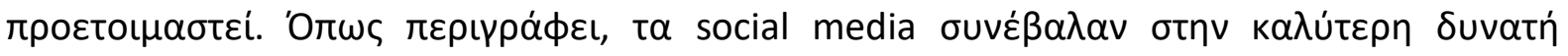

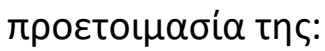

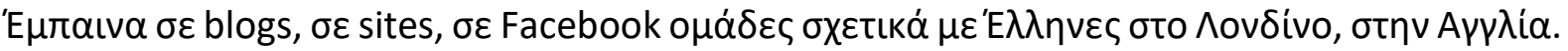

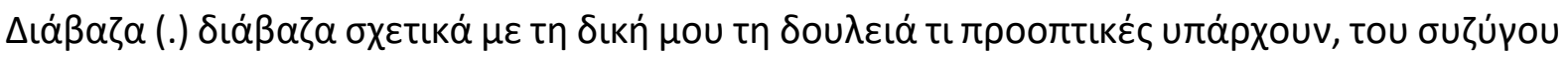

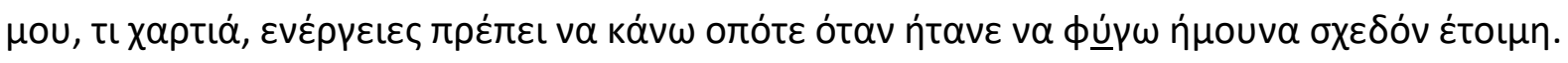

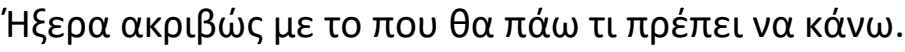

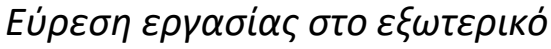

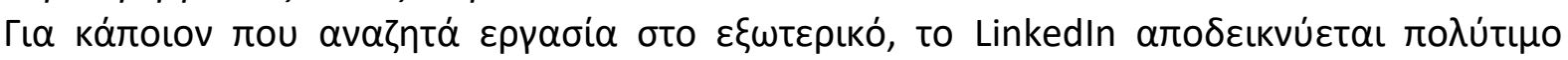

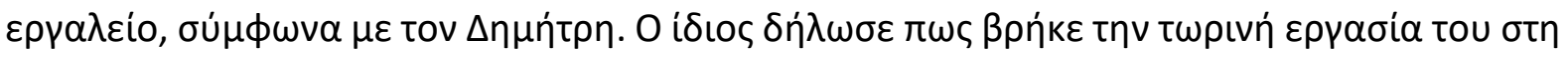

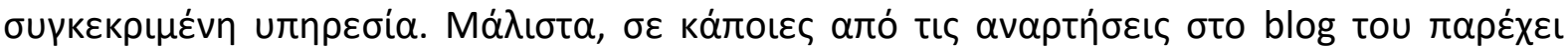

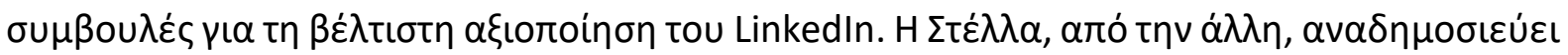

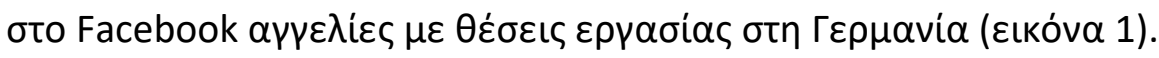

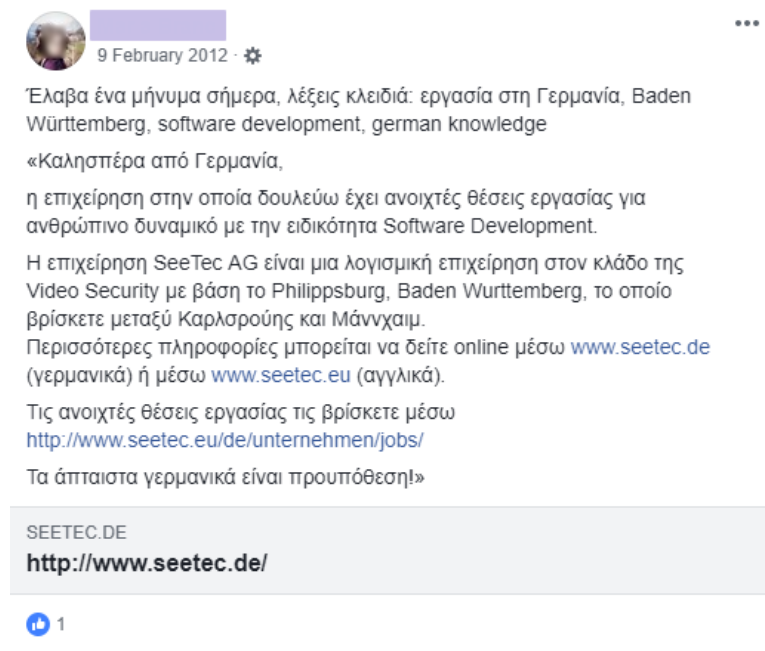

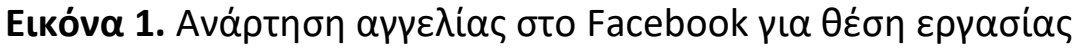

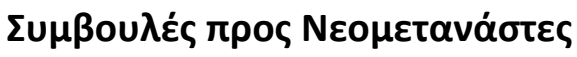

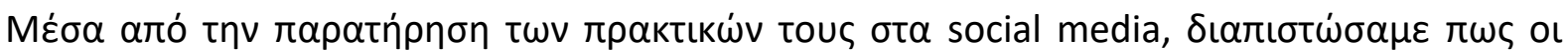

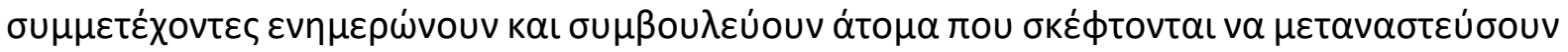

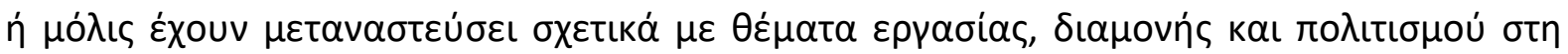

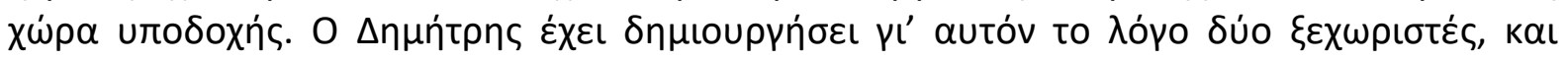




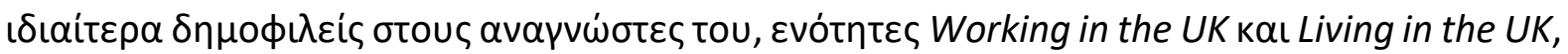

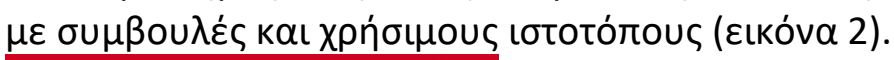

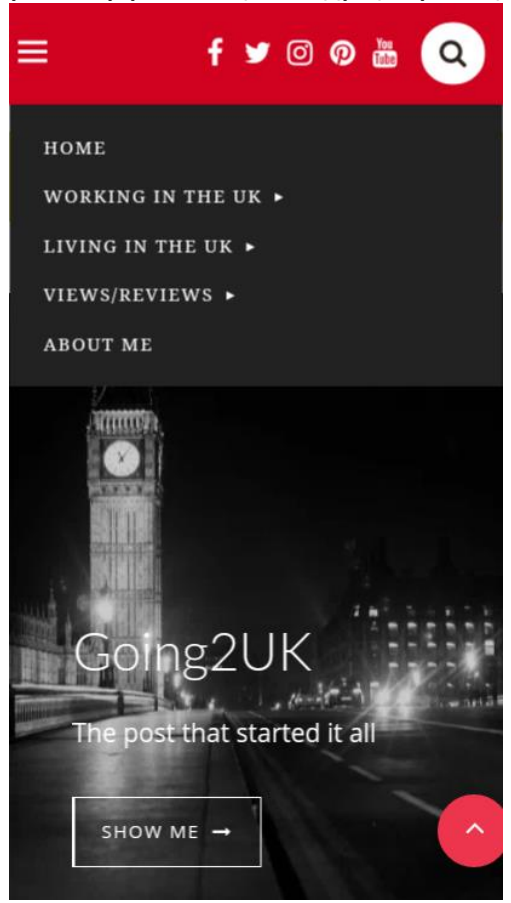

Eıкóva 2. Evótntes Working in the UK кal Living in the UK oto blog fromgr2uk

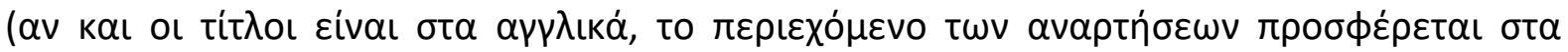
$\left.\varepsilon \lambda \lambda \eta \vee \alpha_{\alpha}\right)$

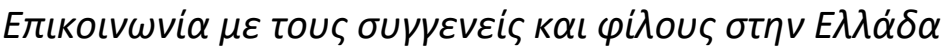

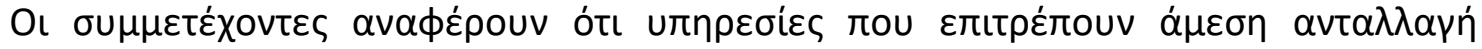

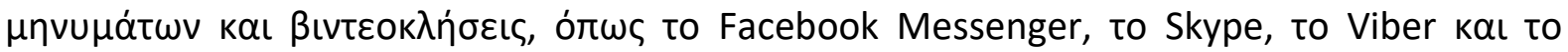

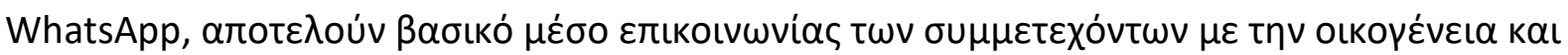

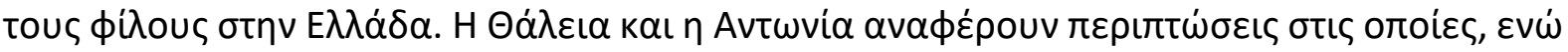

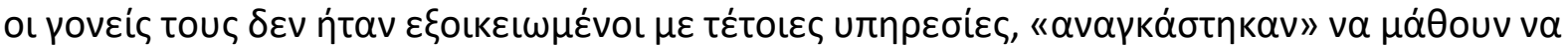

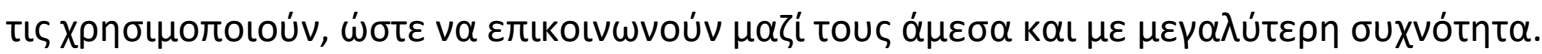

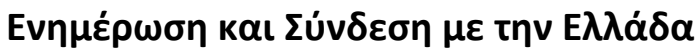

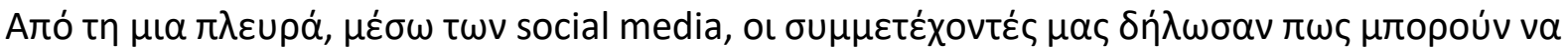

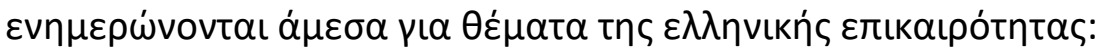

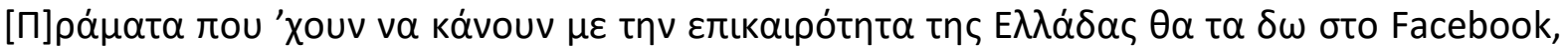

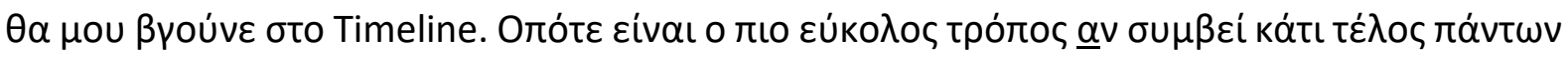

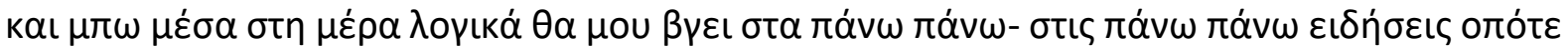
$\theta \alpha$ то $\mu \alpha \dot{\theta} \theta \omega$.

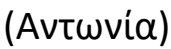

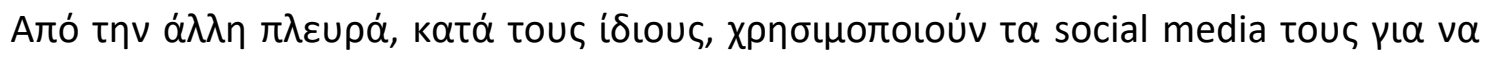

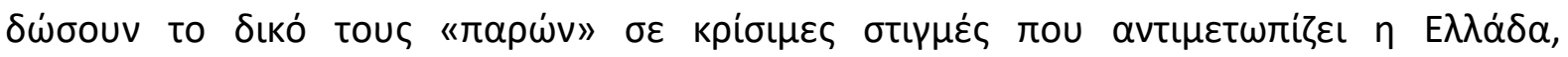

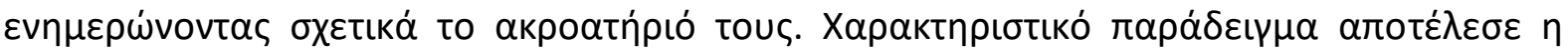

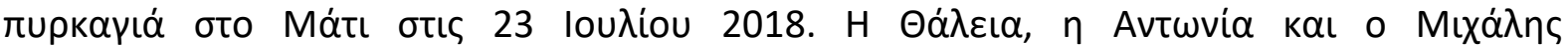

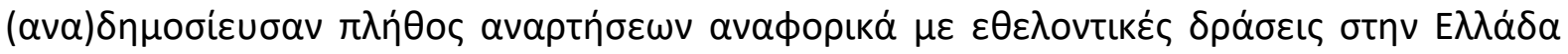




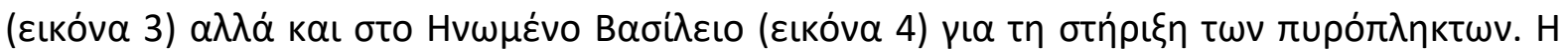

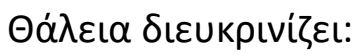

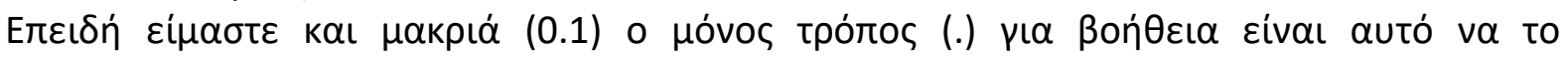

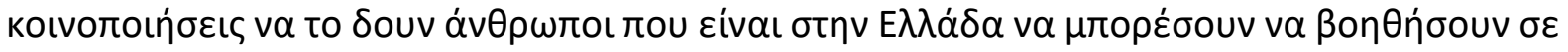

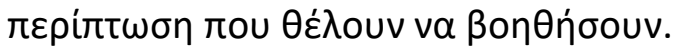

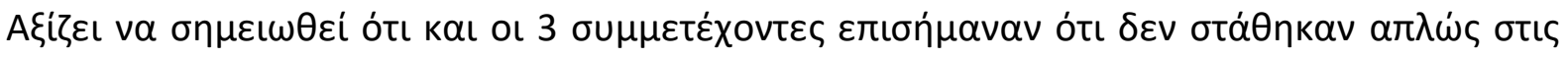

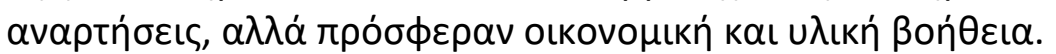

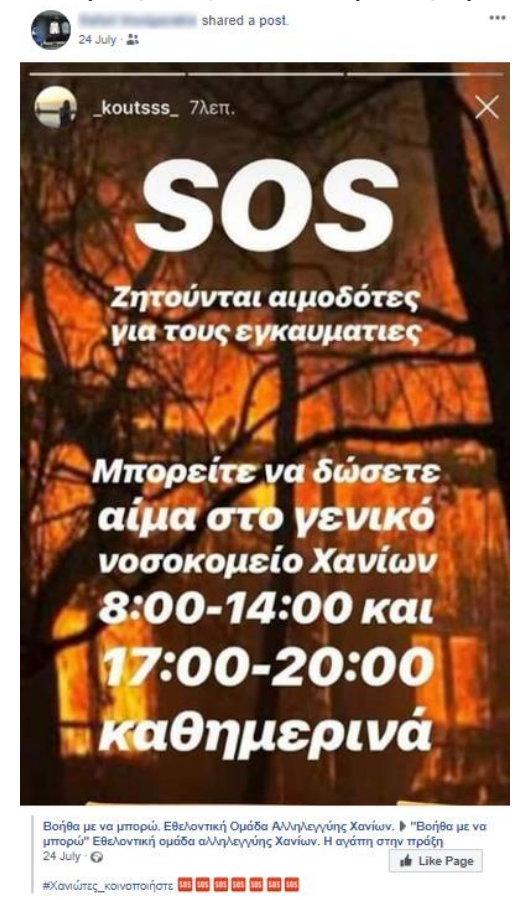

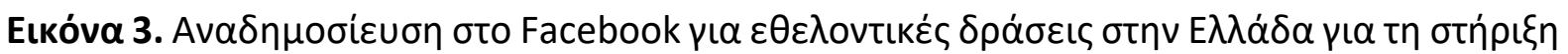

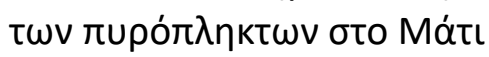

25 July $2018 \cdot \ddot{*}$

To all our friends from Oxford:

We have 2 collection points to gather products of high demand for those

affected by the wildfires in Greece.

1) Department of Biochemistry, 2) Department of Oncology.

A detailed list of products required is attached. Thank you in advance

A OUGS Oxford University Greek Society updated their status.

黄 25 July $2018 \cdot 8$

There are now two collection points in Oxford in order to gather products of high demand.

The first collection point will be at Rodney Porter Building at the D...

See more

(1) 3

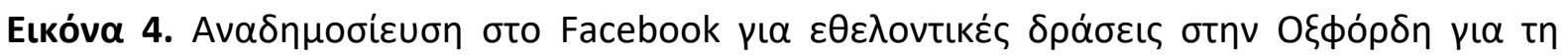

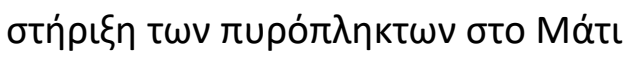

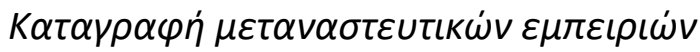

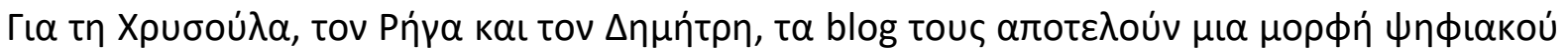

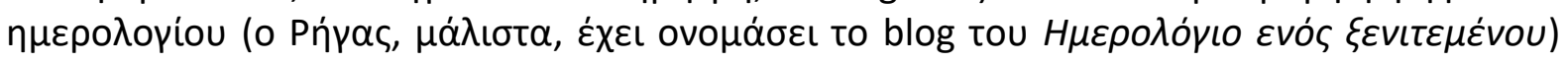




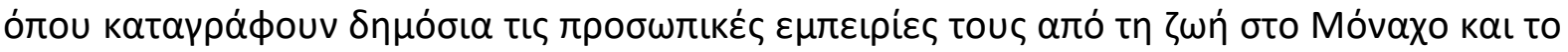

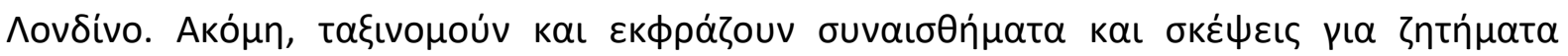

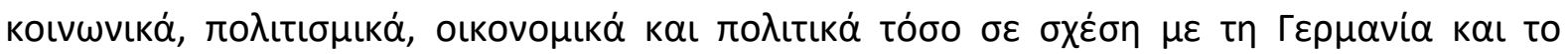

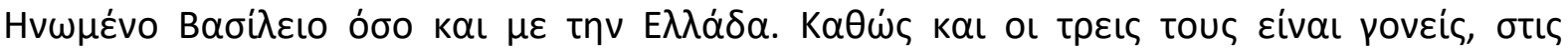

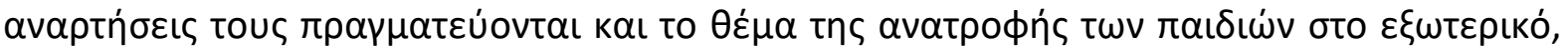

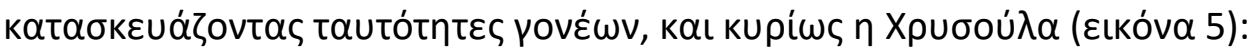

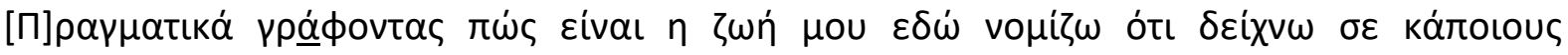

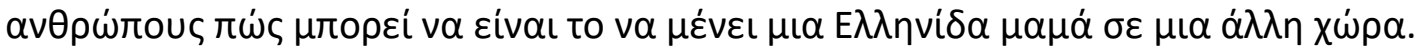

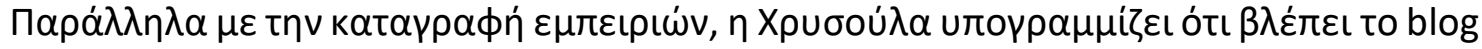

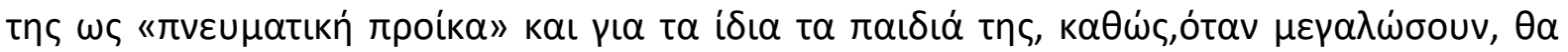

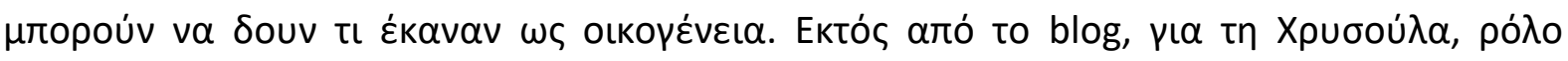

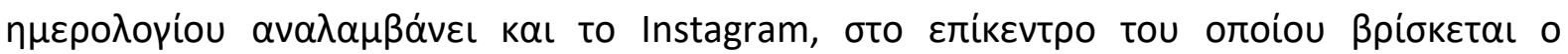

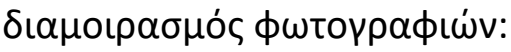

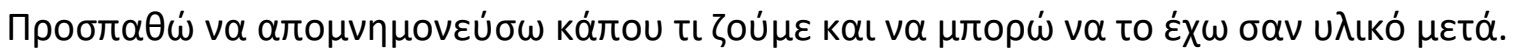
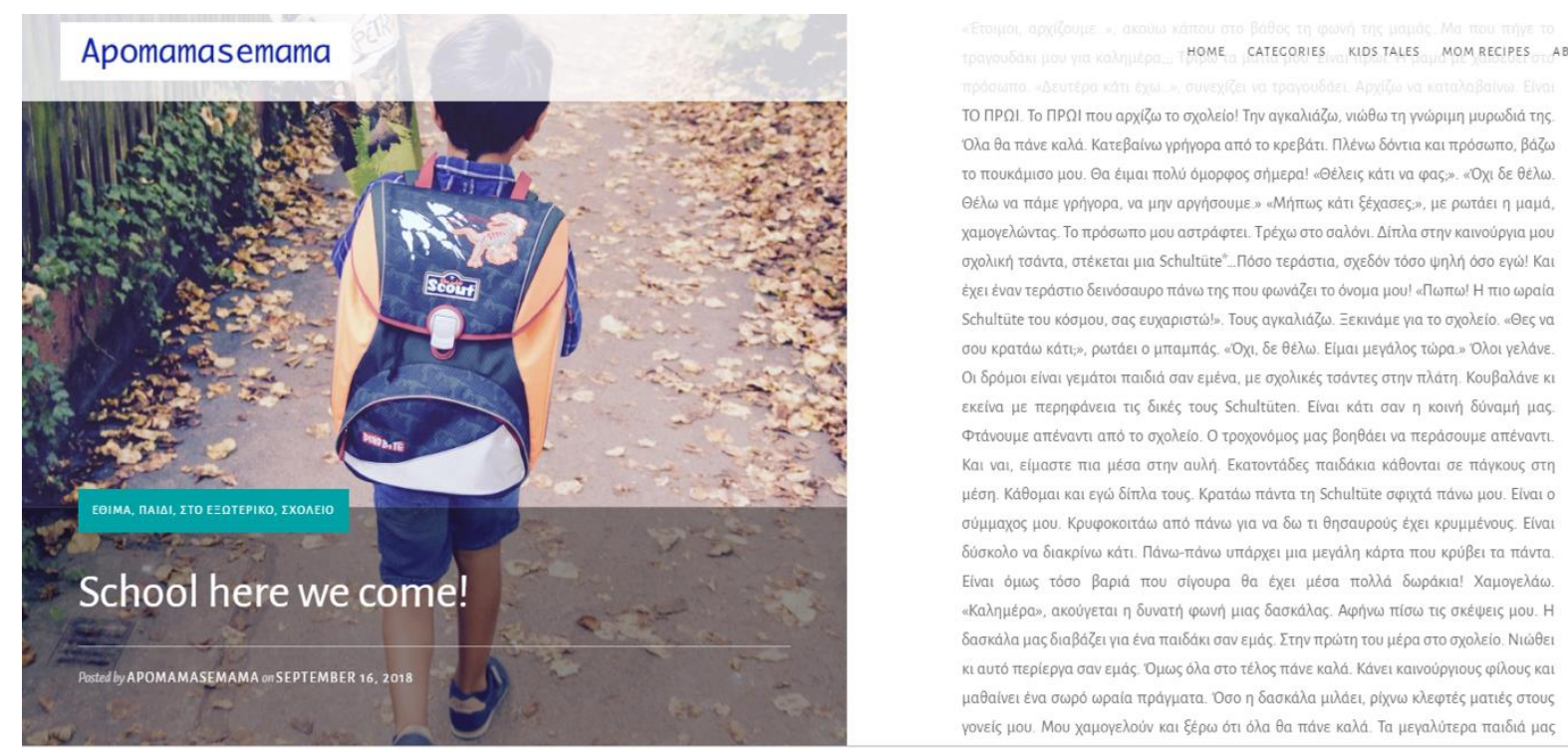

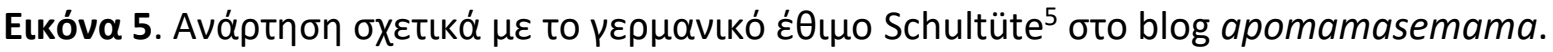

\section{Парпүорıа́}

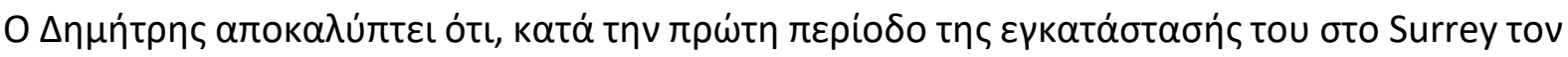

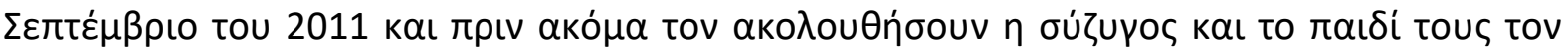

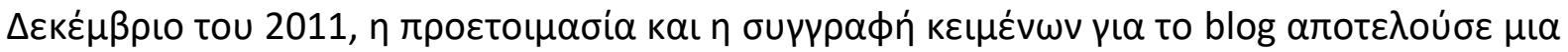

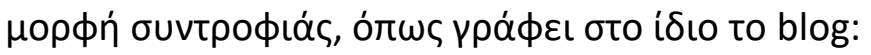

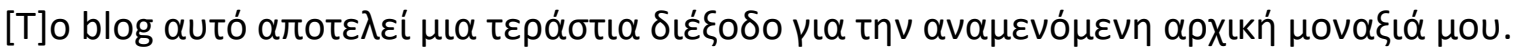

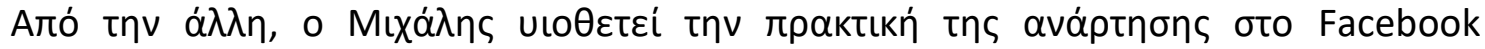

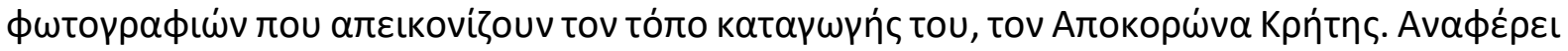

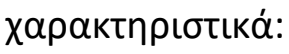

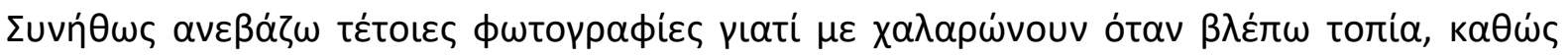

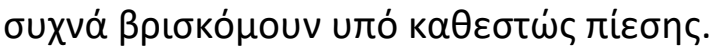

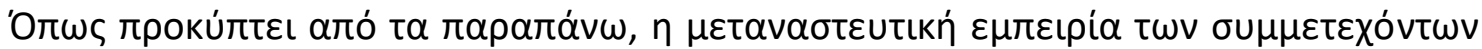

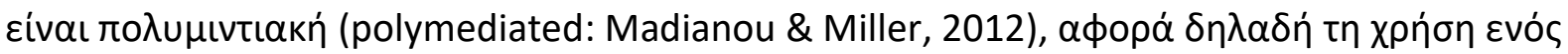

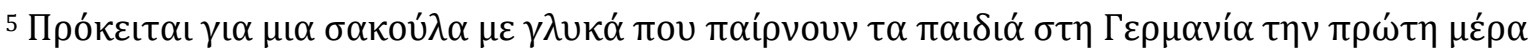

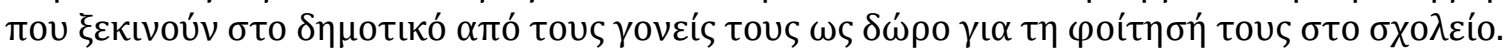




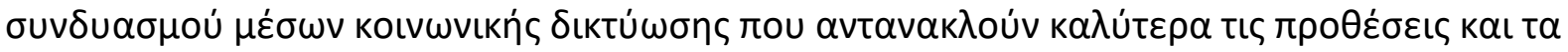

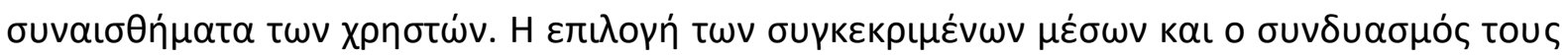

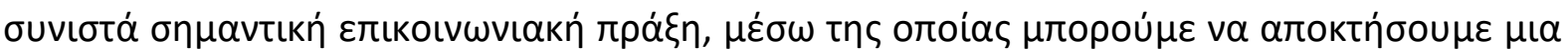

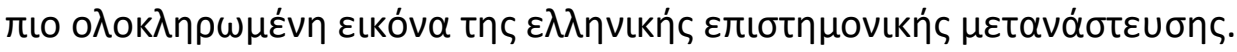

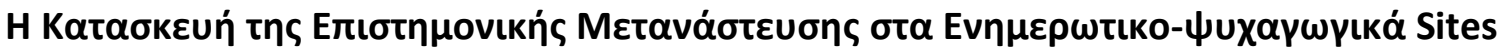

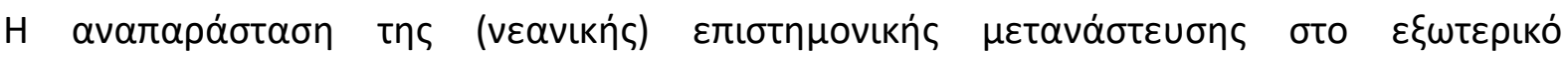

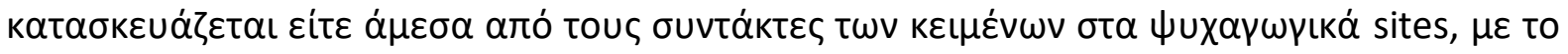

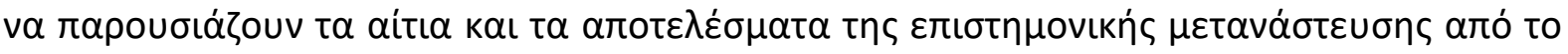

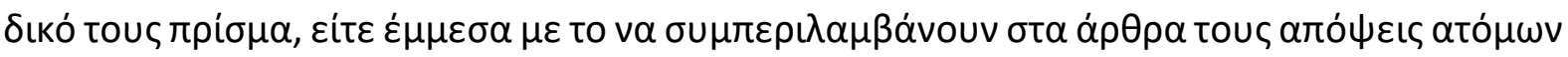

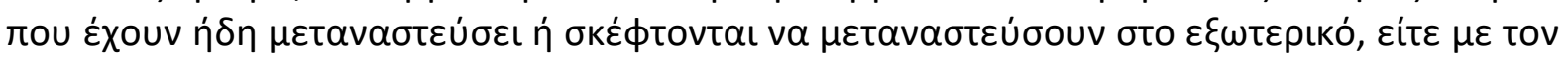

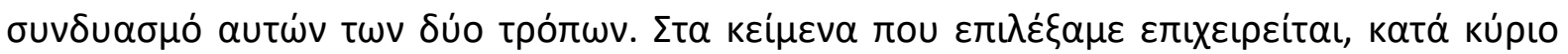

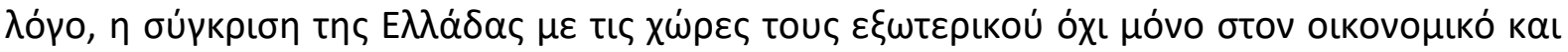

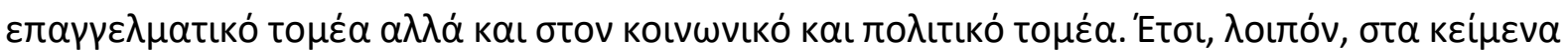

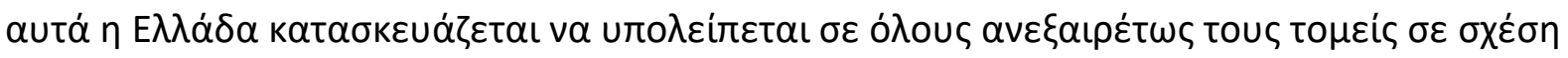

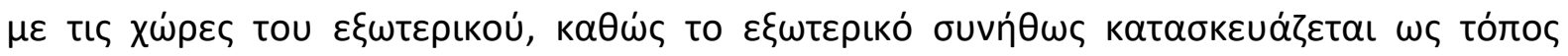

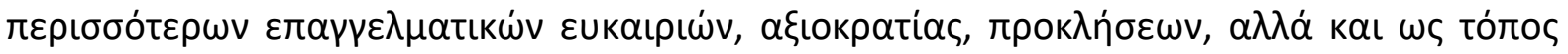

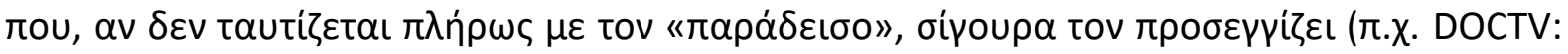

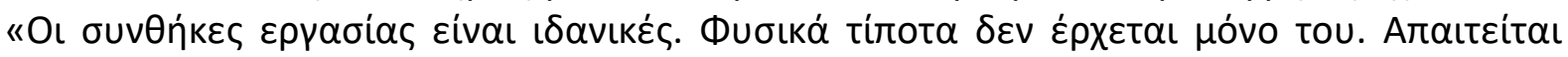

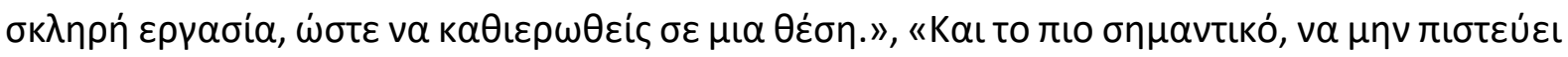

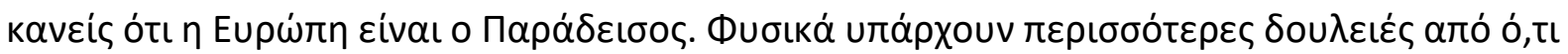

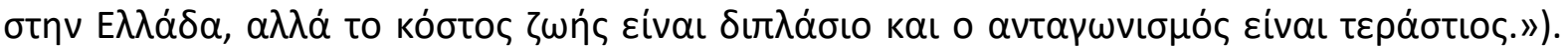

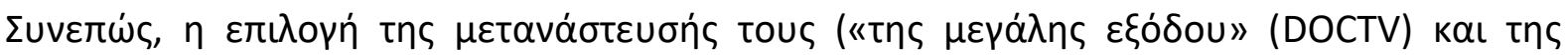

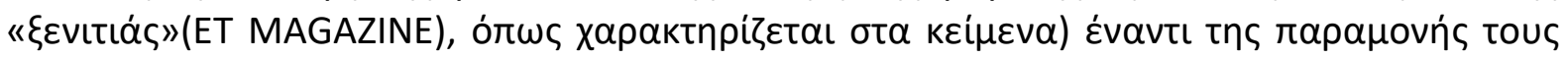

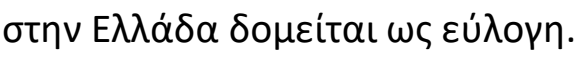

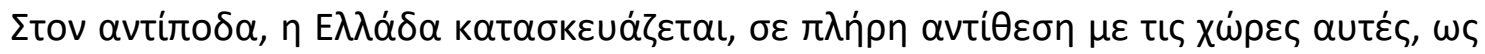

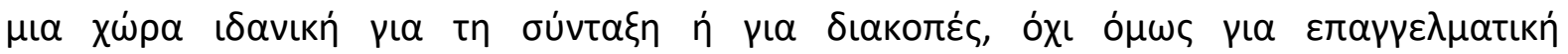

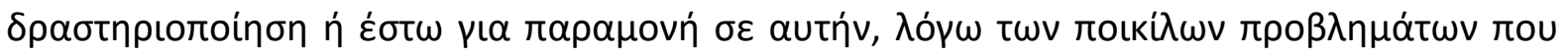

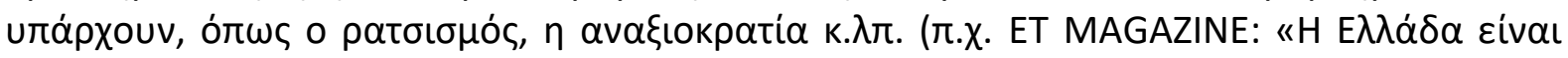

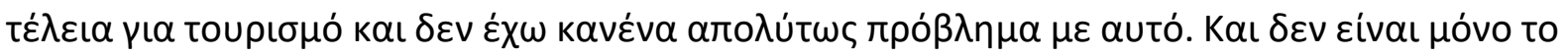

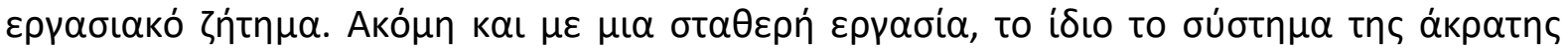

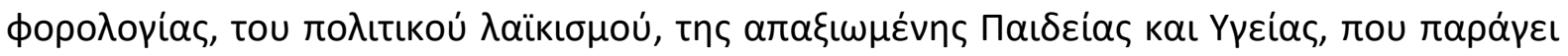

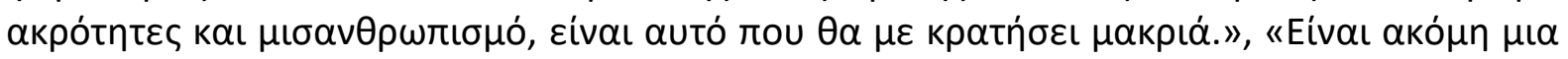

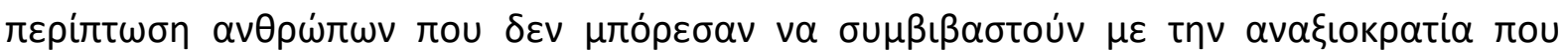

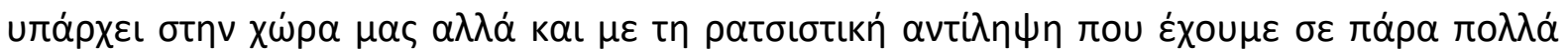

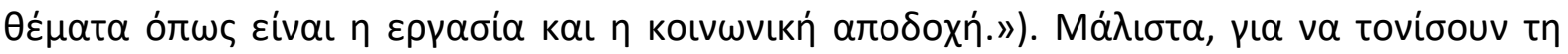

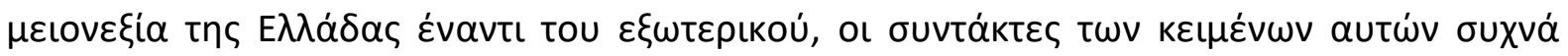

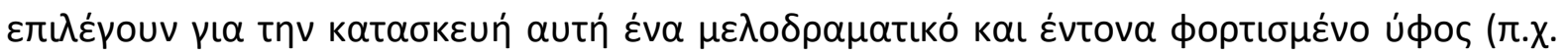

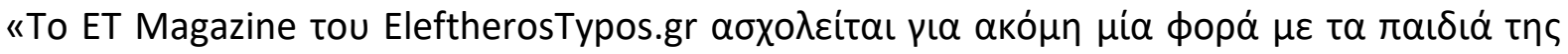

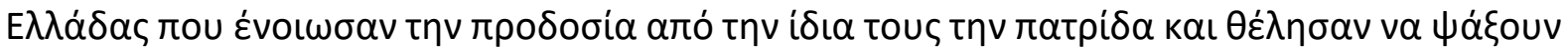

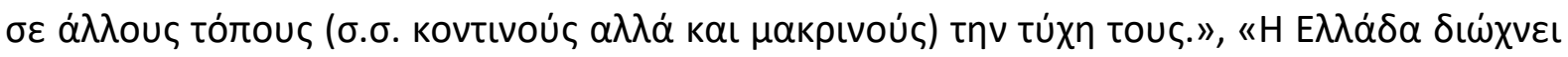

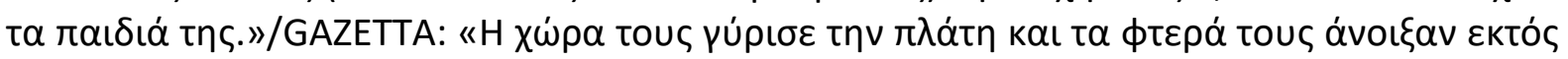

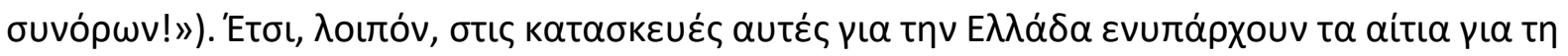

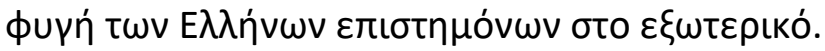

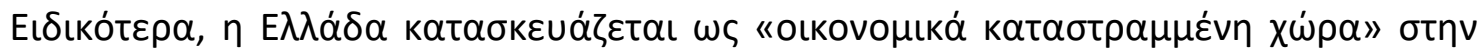

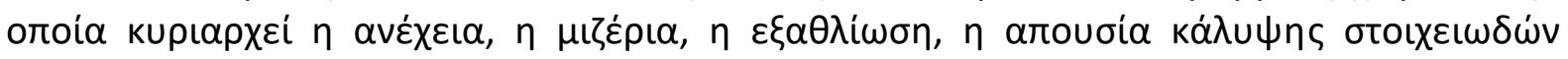

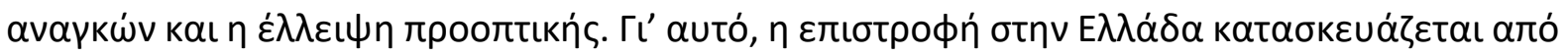




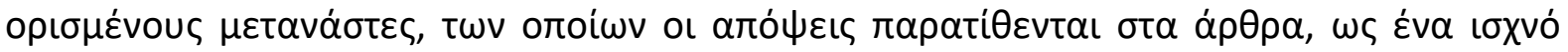

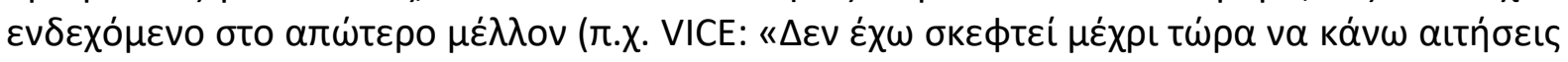

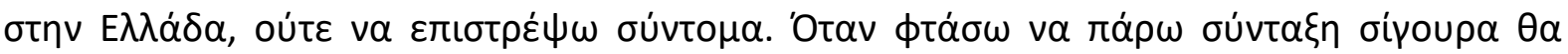

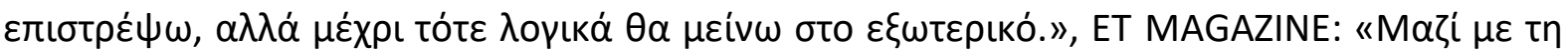

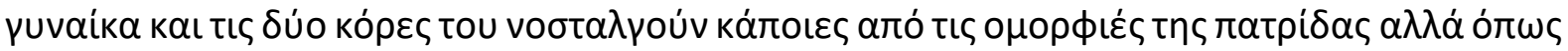

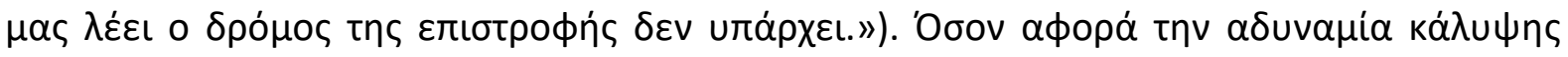

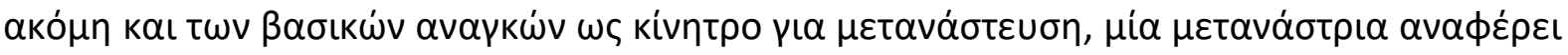

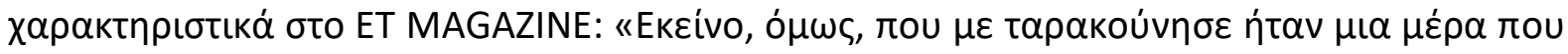

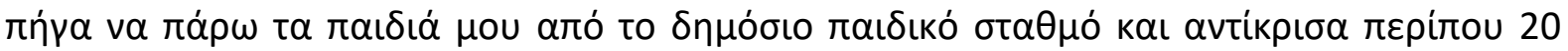

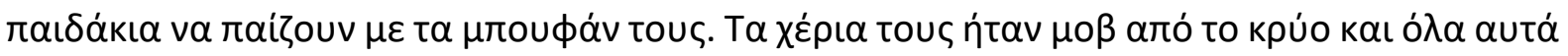

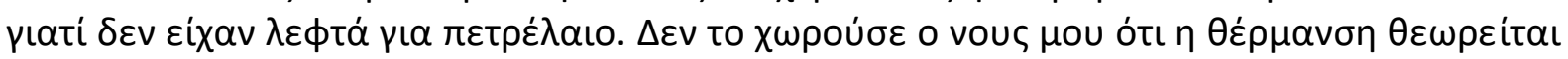

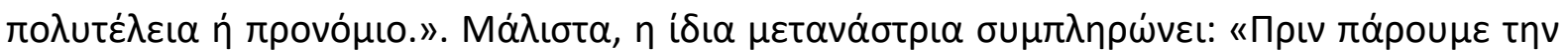

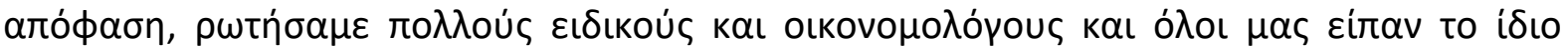

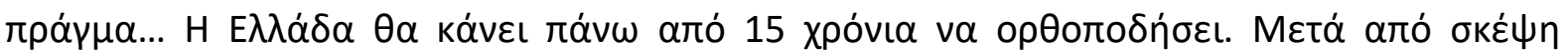

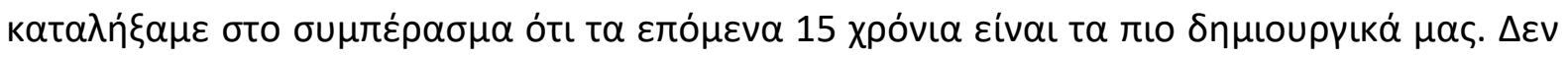

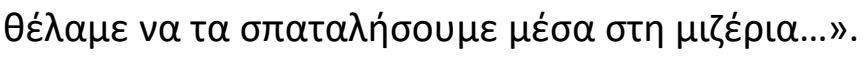

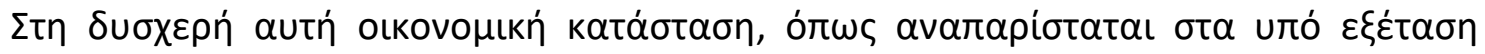

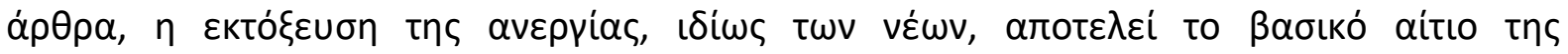

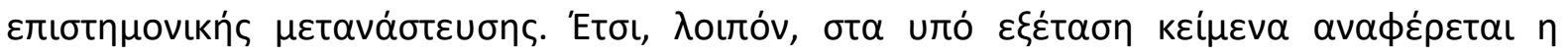

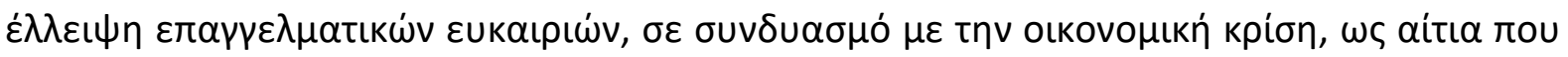

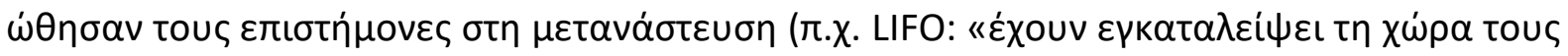

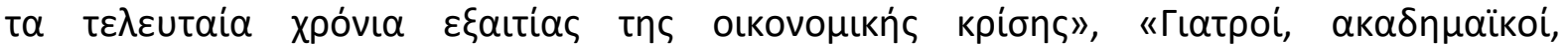

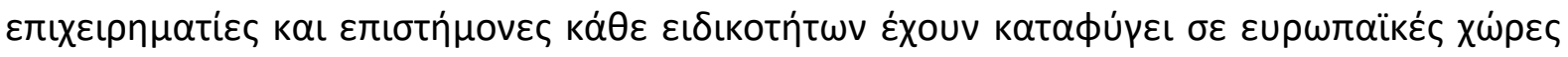

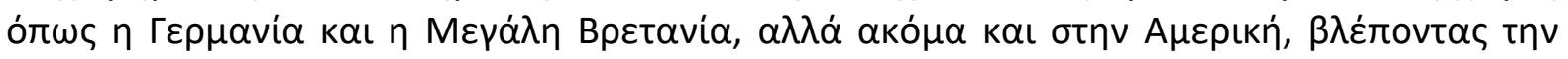

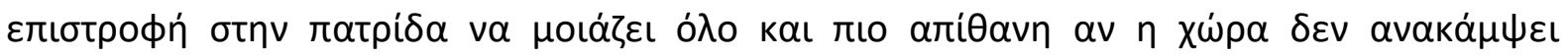

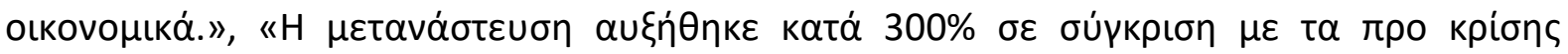

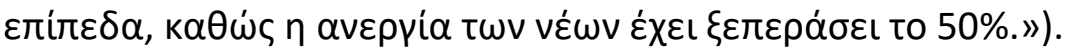

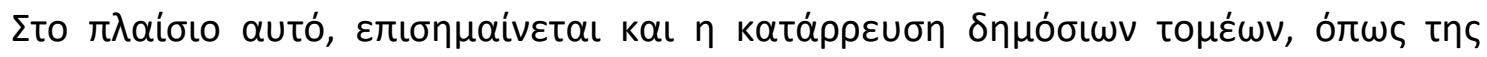

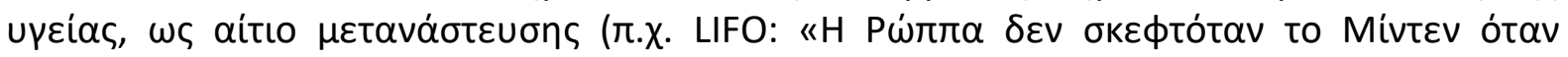

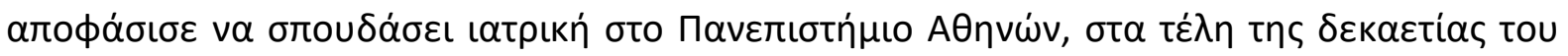

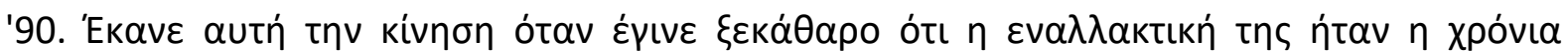

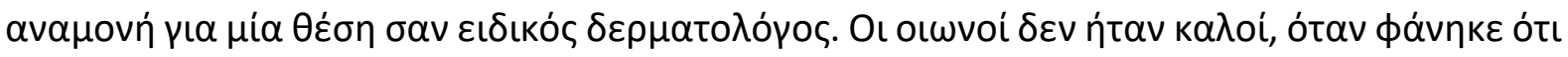

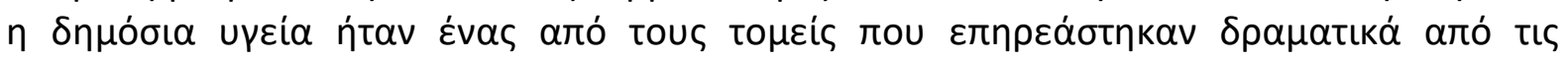

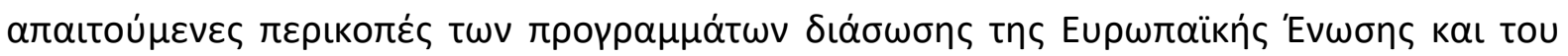

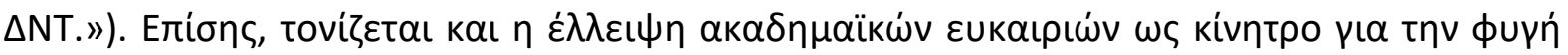

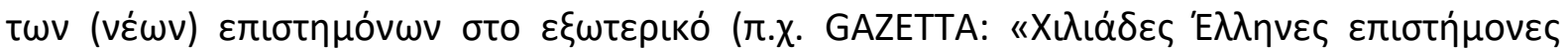

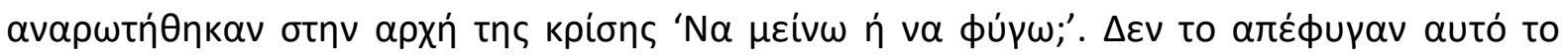

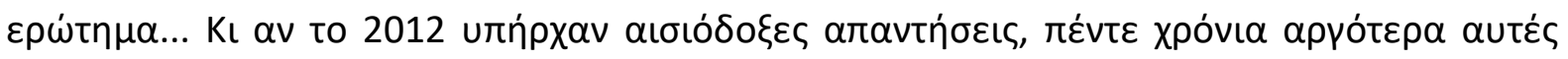

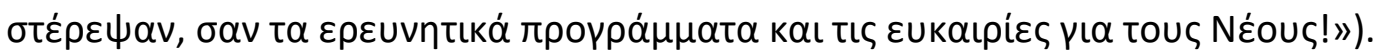

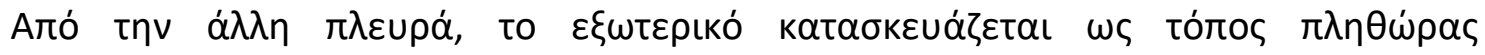

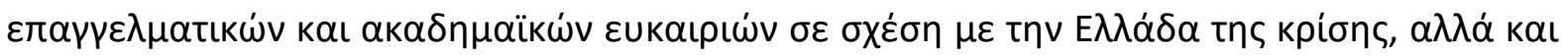

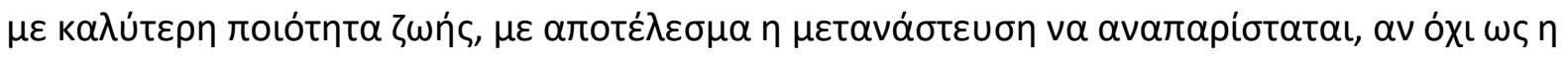

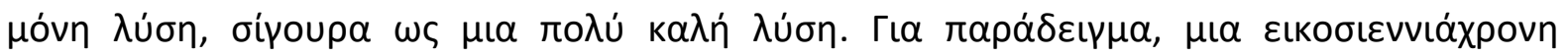

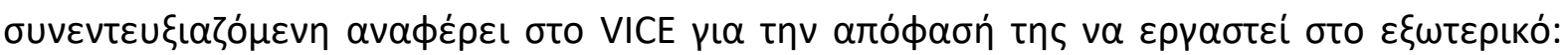

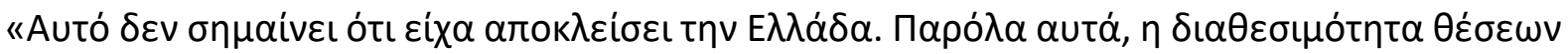

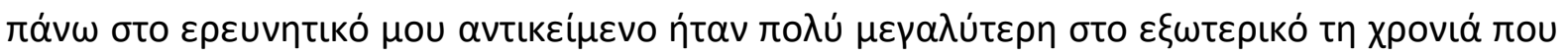

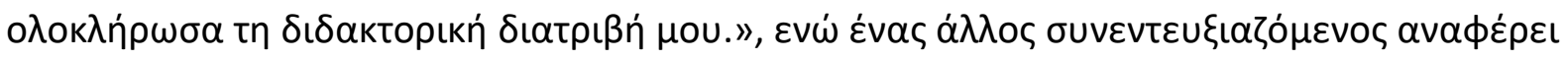




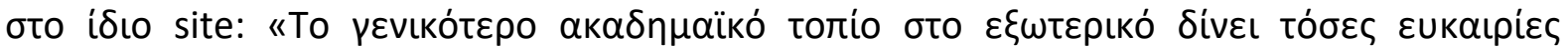

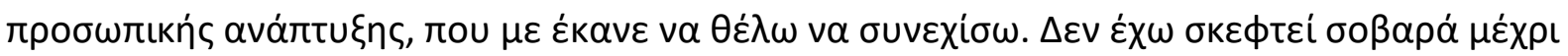

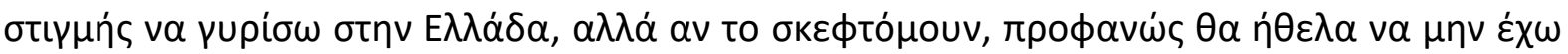

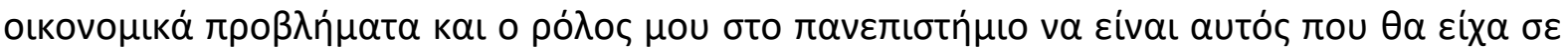

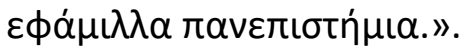

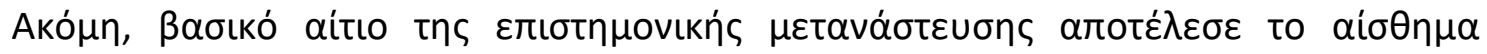

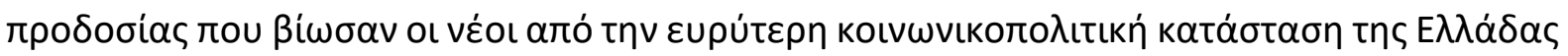

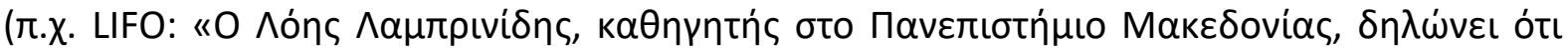

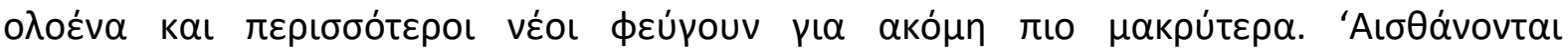

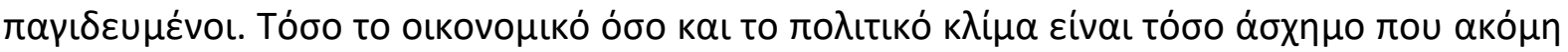

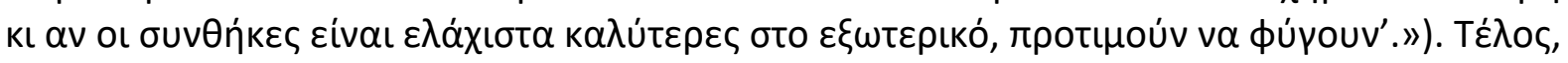

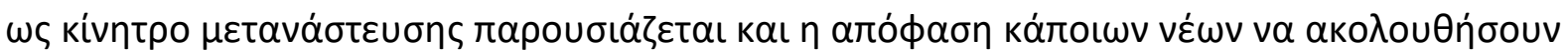

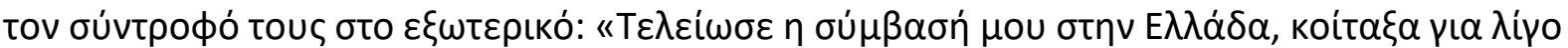

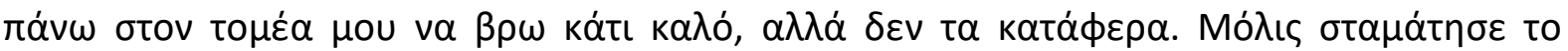

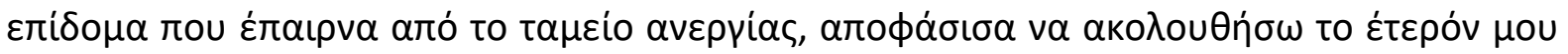

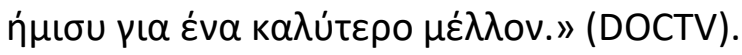

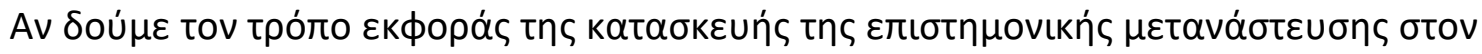

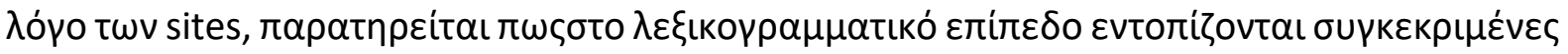

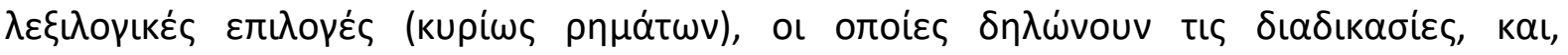

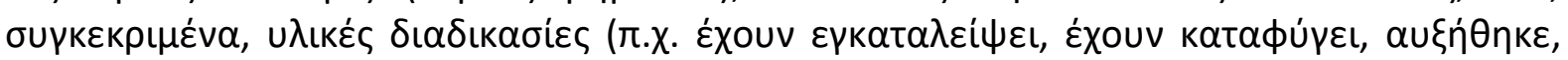

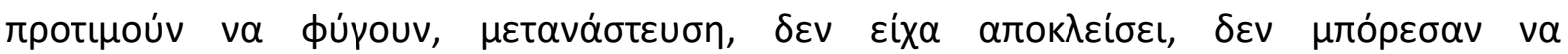

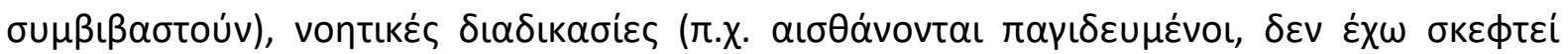

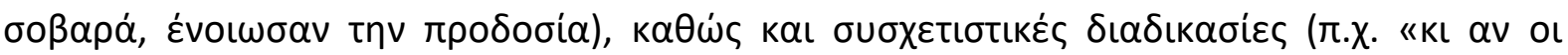

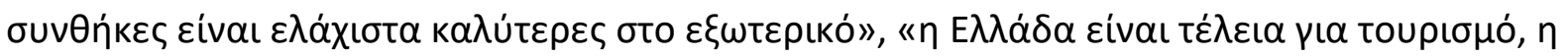

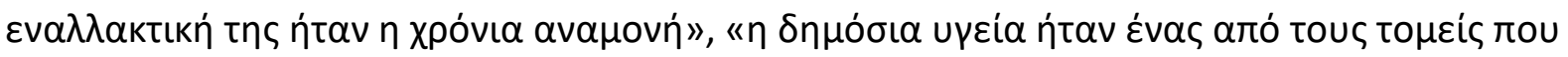

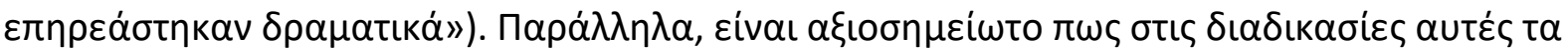

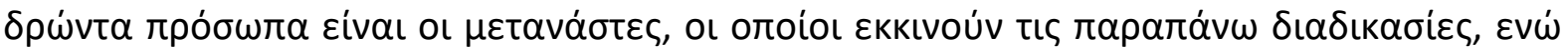

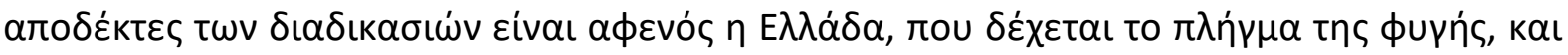

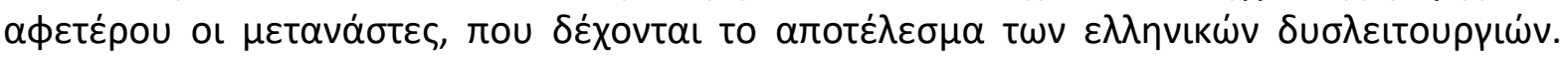

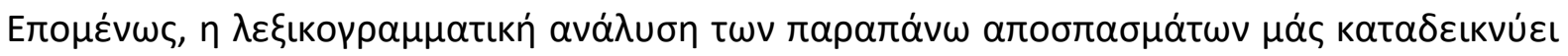

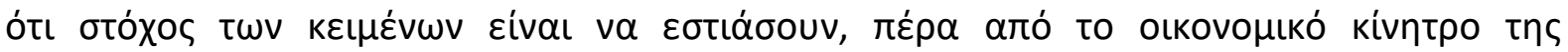

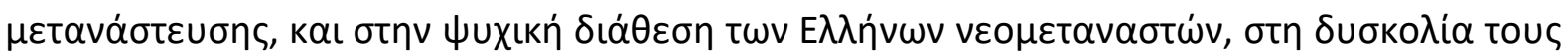

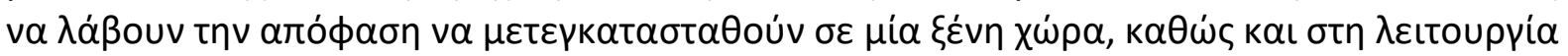

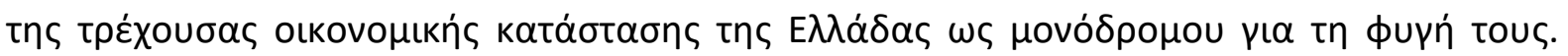

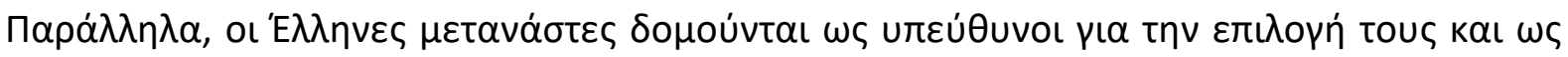

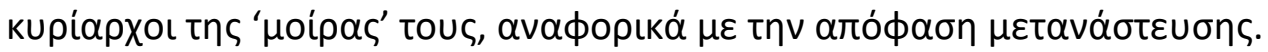

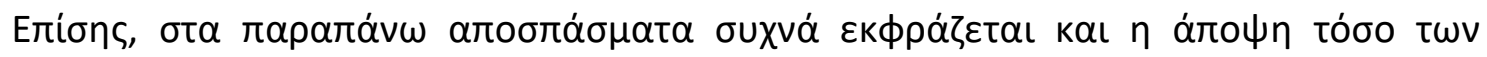

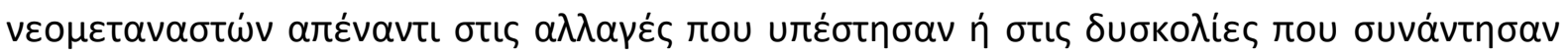

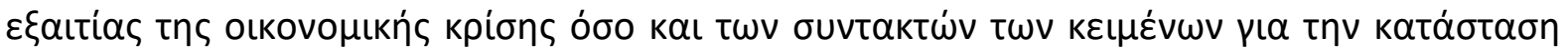

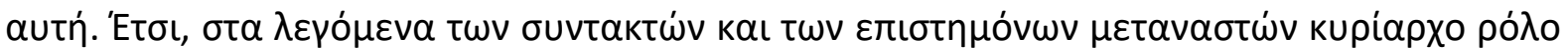

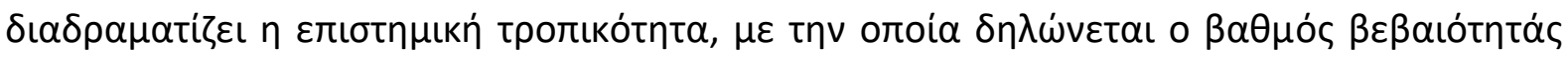

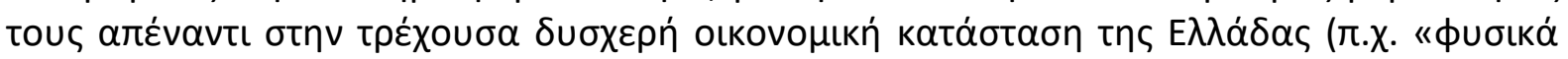

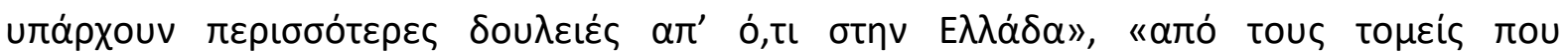

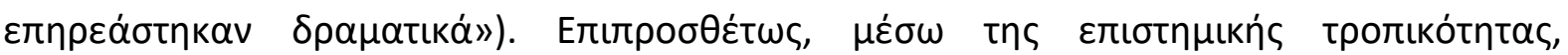

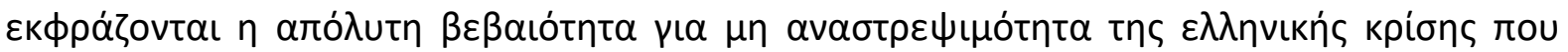

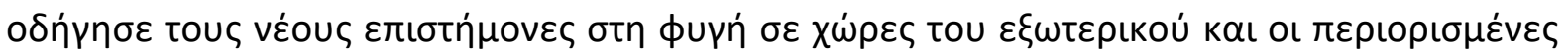

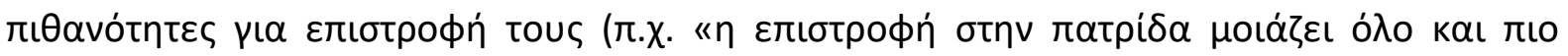




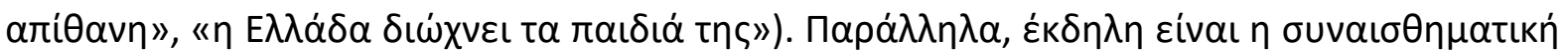

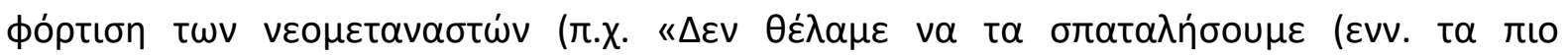

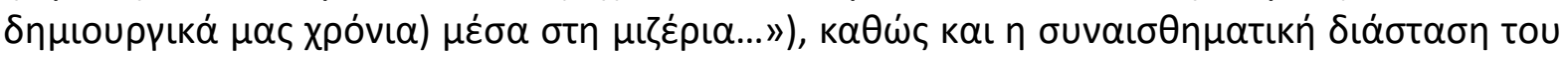

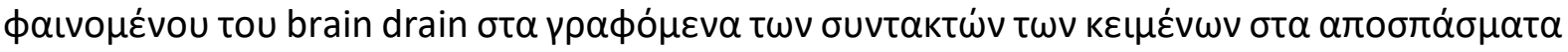

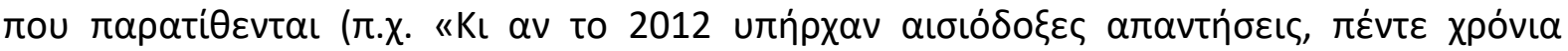

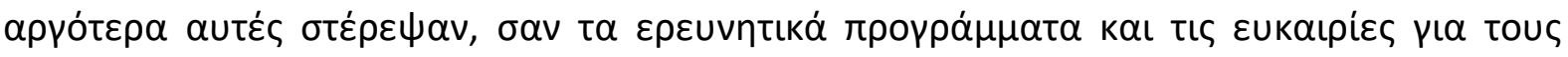

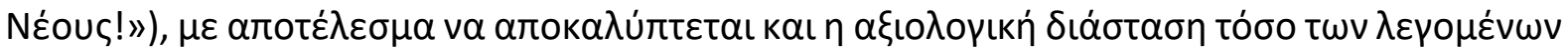

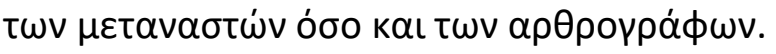

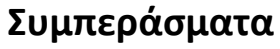

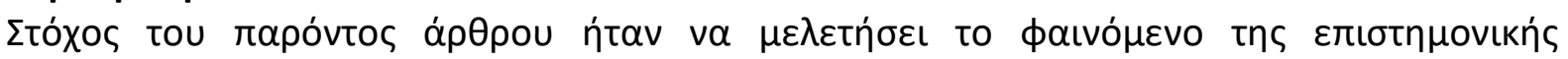

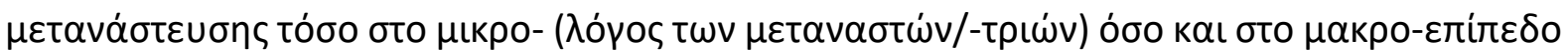

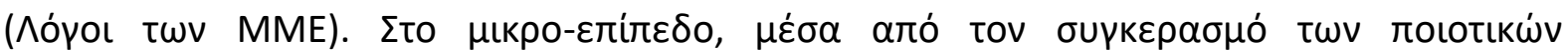

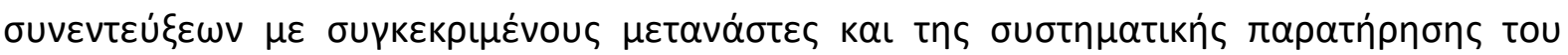

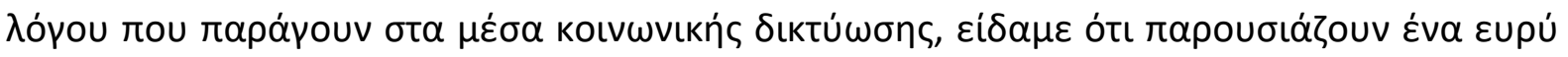

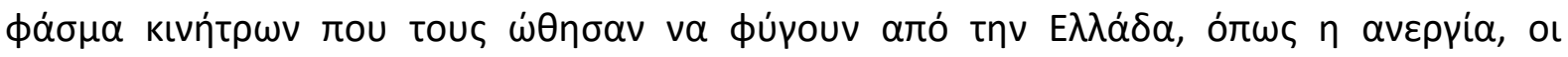

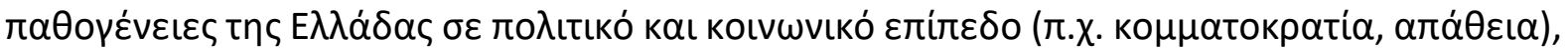

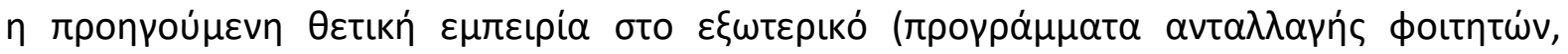

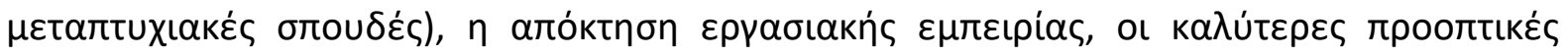

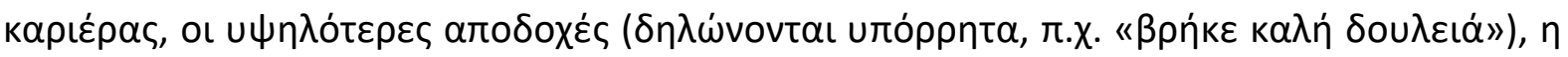

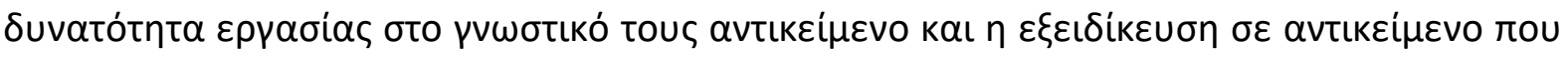

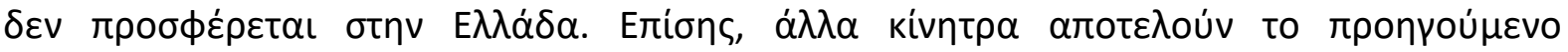

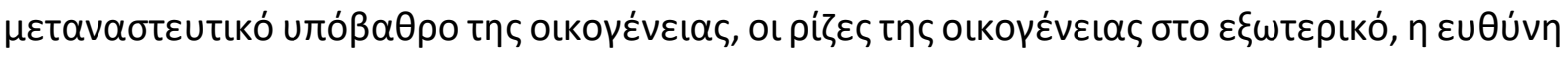

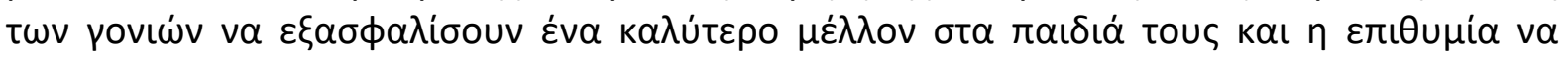

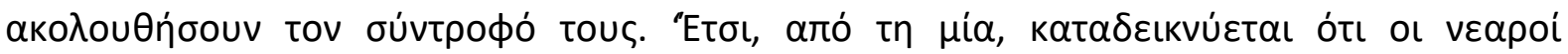

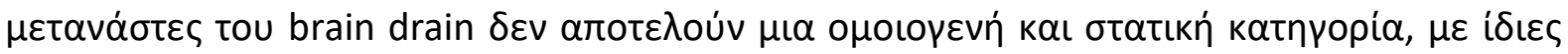

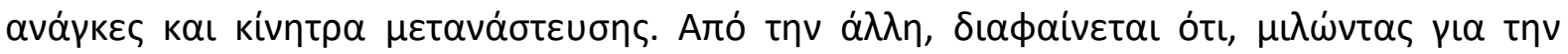

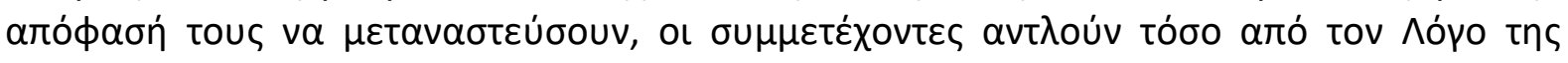

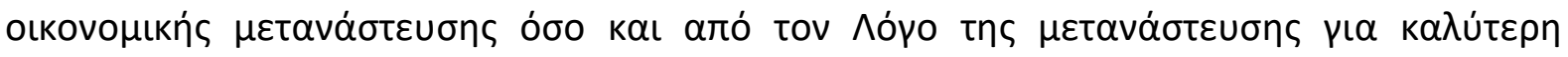

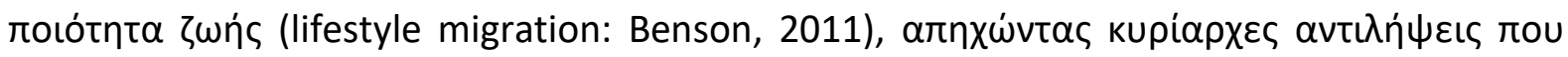

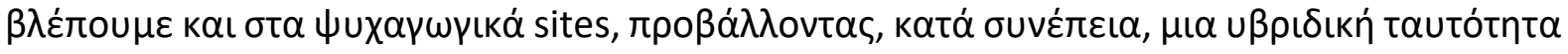

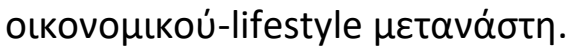

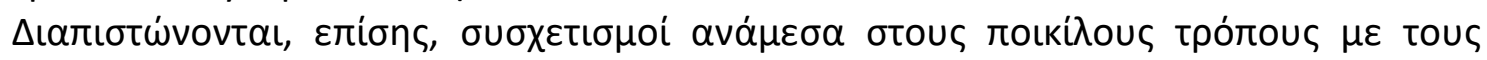

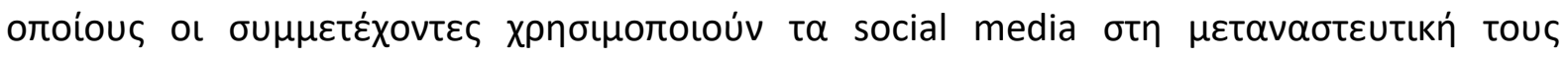

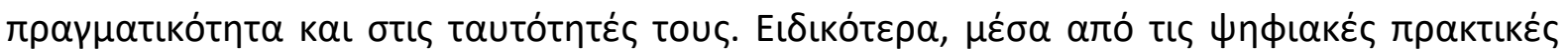

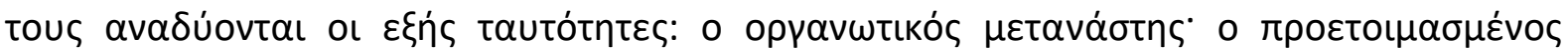

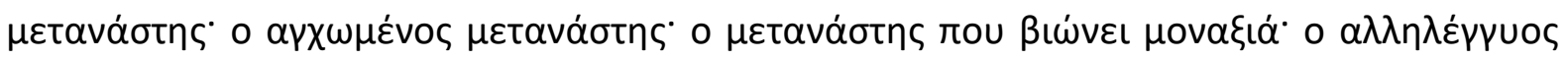

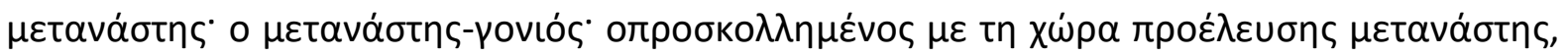

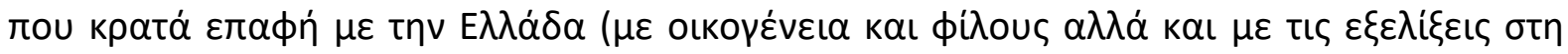

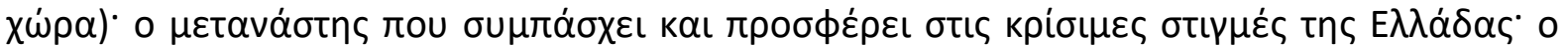

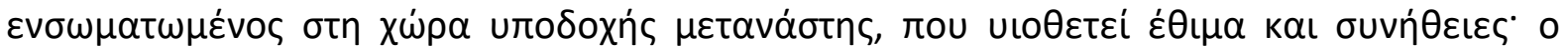

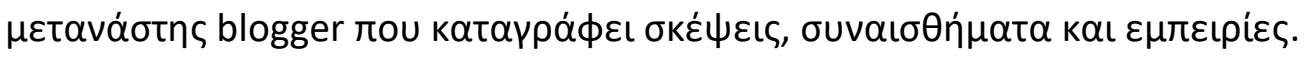

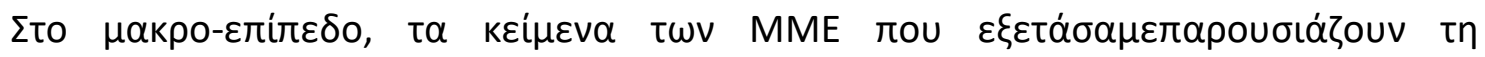

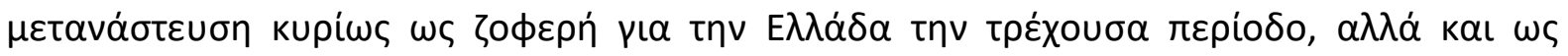

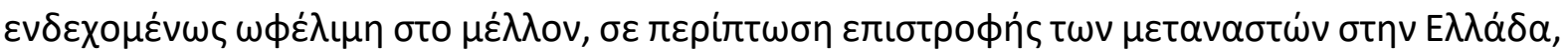

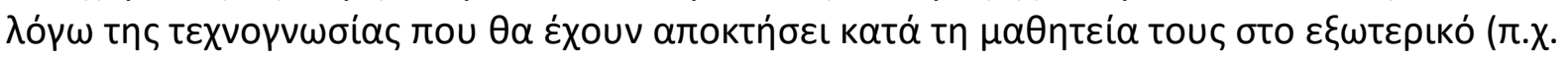

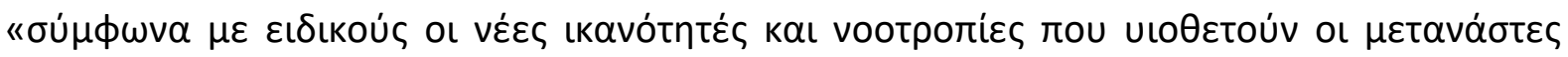




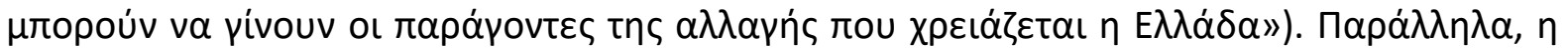

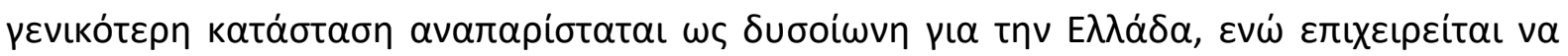

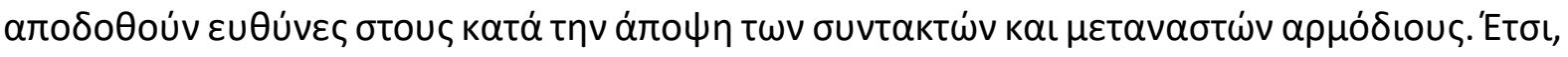

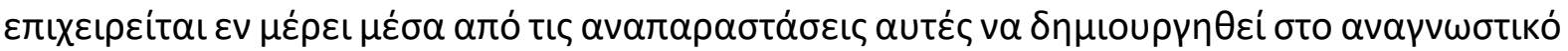

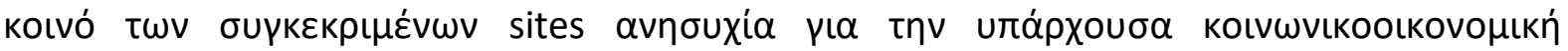

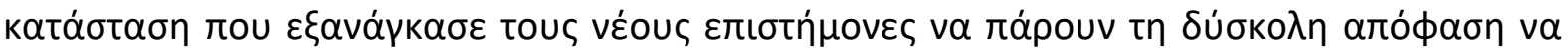

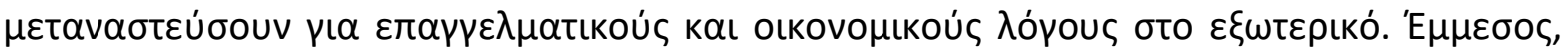

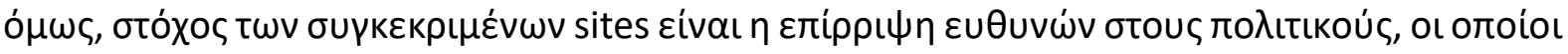

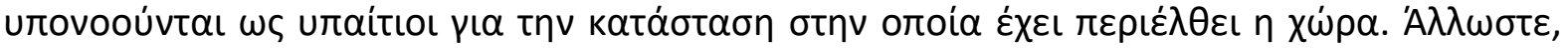

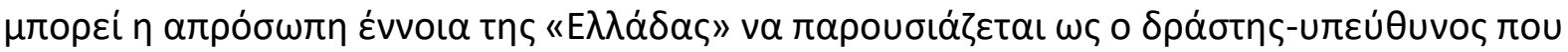

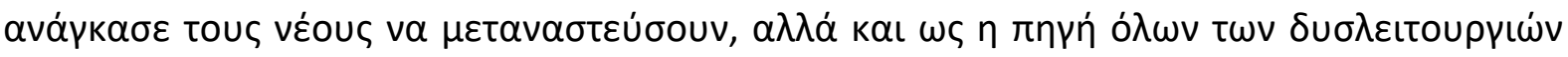

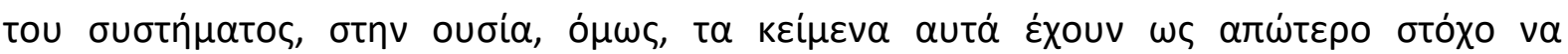

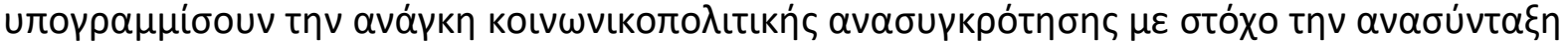

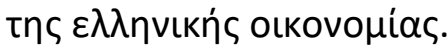

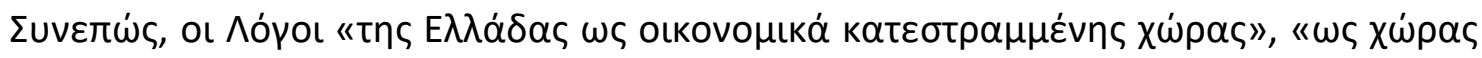

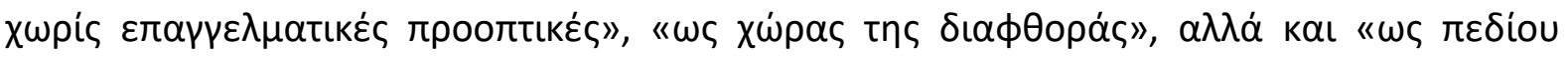

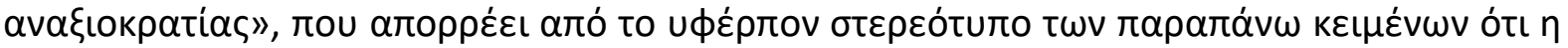

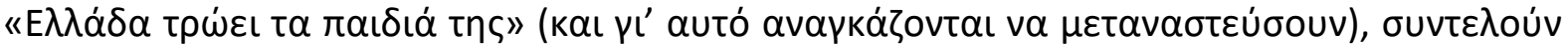

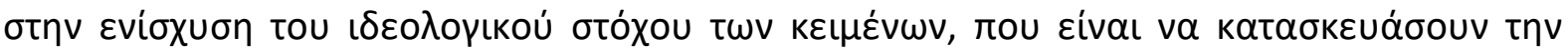

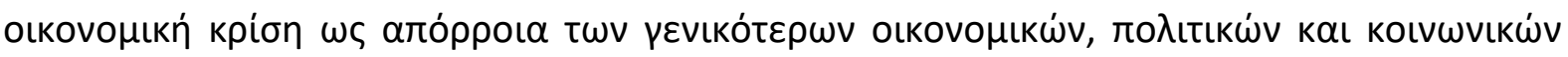

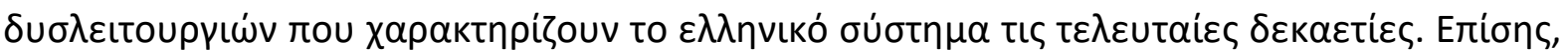

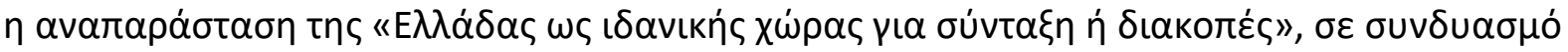

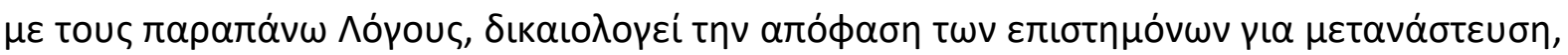

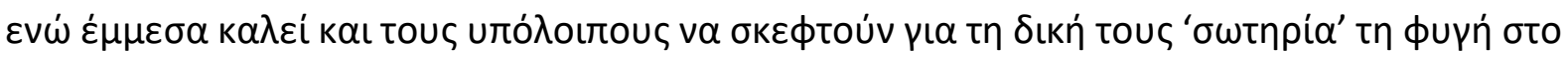

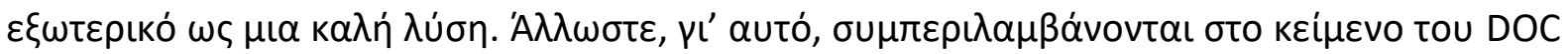

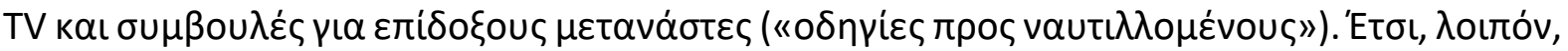

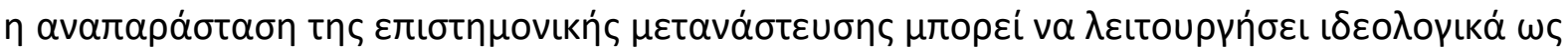

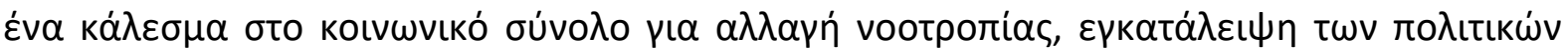

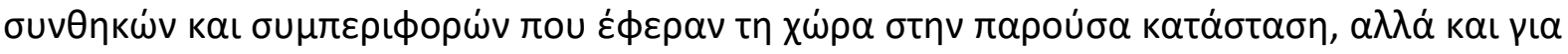

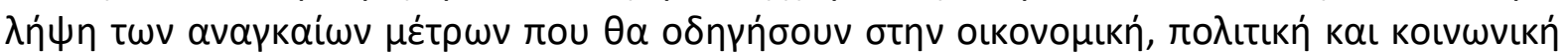

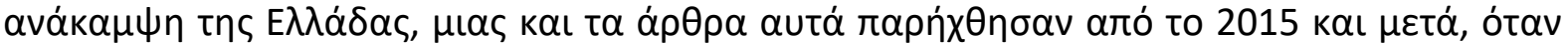

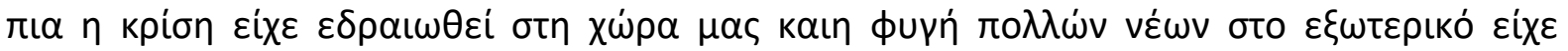

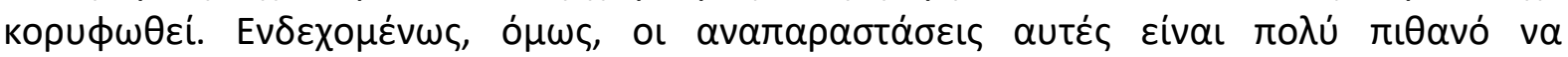

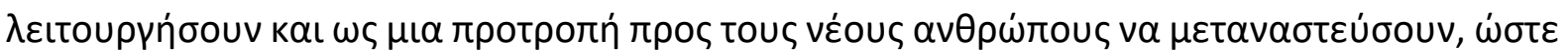

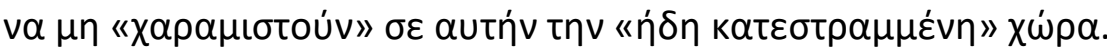

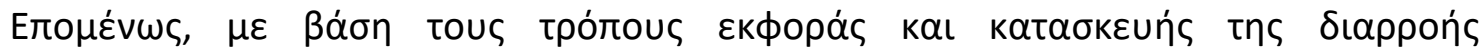

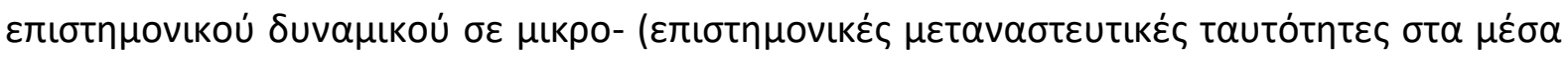

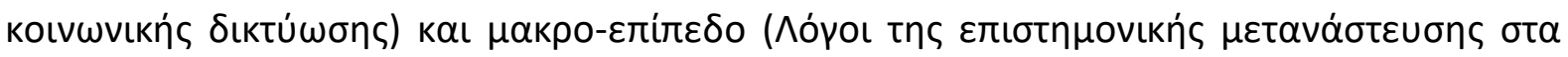

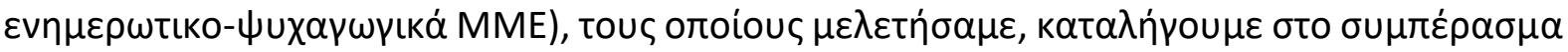

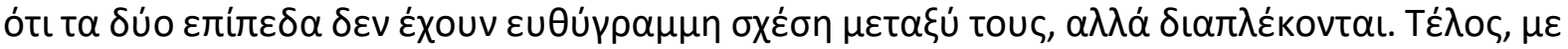

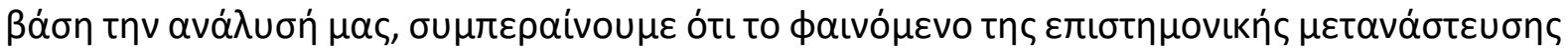

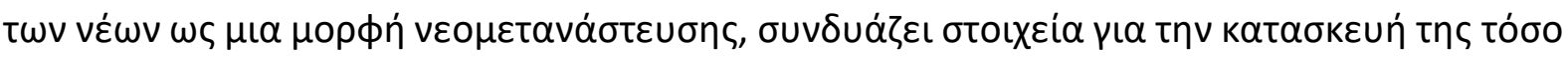

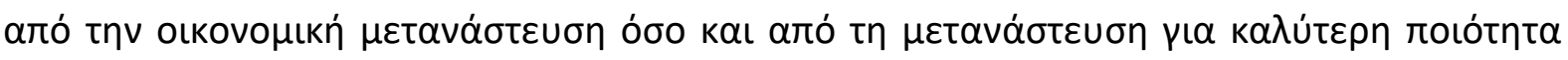

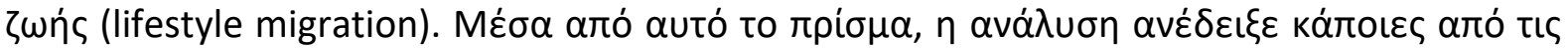




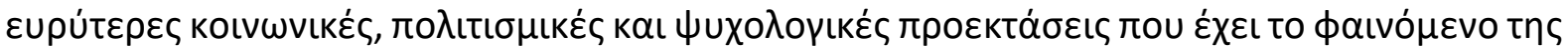

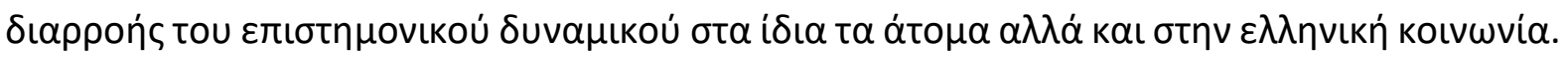

\section{Euxapiotís}

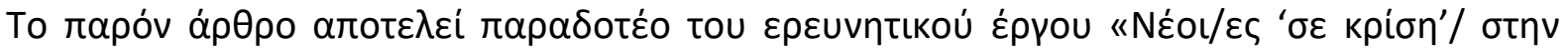

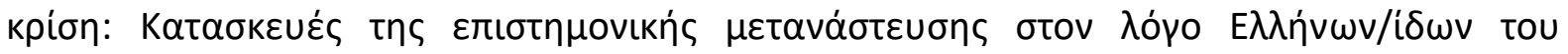

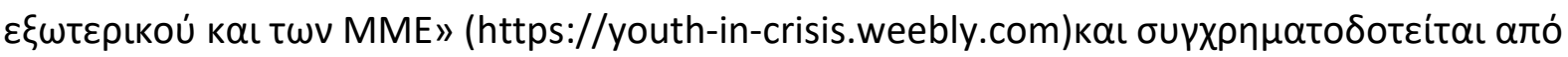

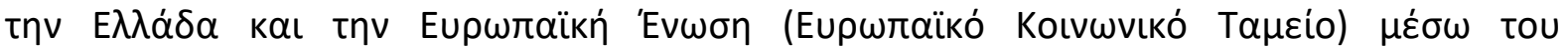

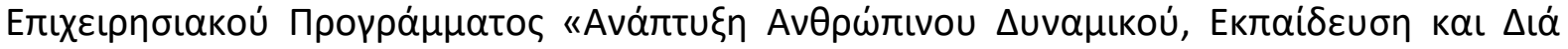

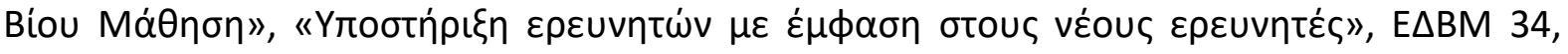
E乏ПA 2014-2020.

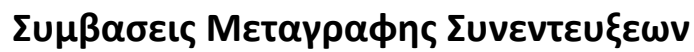

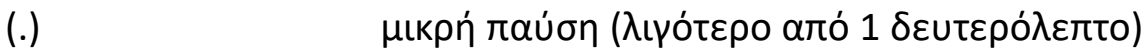

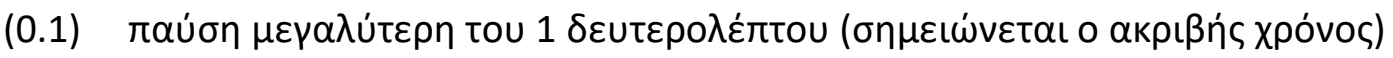

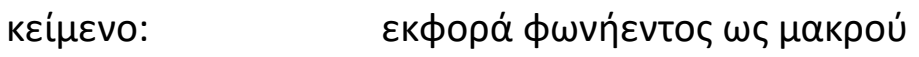

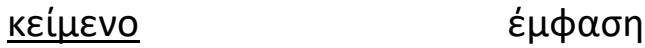

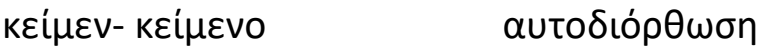

\section{References}

Androutsopoulos, J. (2008). Potentials and Limitations of Discourse-centred Online Ethnography. Language@Internet, 5.

Barker, C., \& Galasinski, D. (2001). Cultural studies and discourse analysis: A dialogue on language and identity. London: Sage.

Barton, D., \& Lee, C. (2013). Language online: Investigating digital texts and practices. London: Routledge.

Benson, M. (2011). The British in rural France: Lifestyle migration and the ongoing quest for a better way of life. Manchester: Manchester University Press.

Benwell, B., \& Stokoe, E. (2006). Discourse and identity. Edinburgh: Edinburgh University Press.

Blommaert, J. (2005). Discourse: A critical introduction. Cambridge: Cambridge University Press.

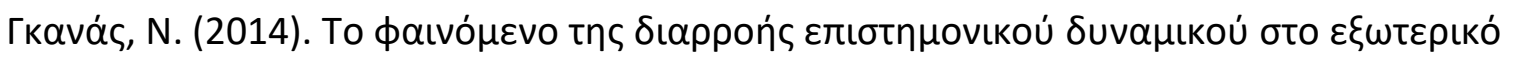

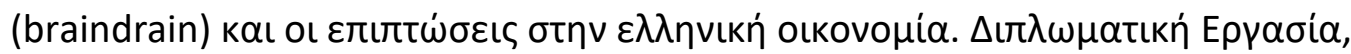

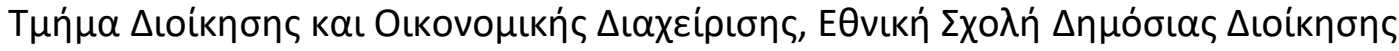

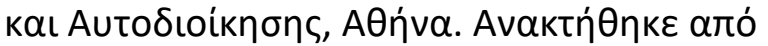

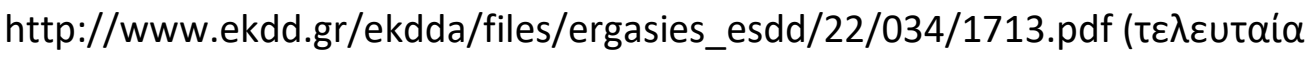

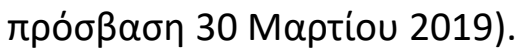

Fairclough, N. (1992). Discourse and social change. Cambridge: Polity Press.

Foucault, M. (2008). The archaeology of knowledge. London: Routledge.

Gee, J. P. (2012). Social linguistics and literacies ( $4^{\text {th }}$ edition). Abingdon: Routledge.

Georgalou, M. (2017). Discourse and identity on Facebook. London: Bloomsbury.

Halliday, M. (1994). An introduction to functional grammar ( $2{ }^{\text {nd }}$ edition). London: EdwardArnold.

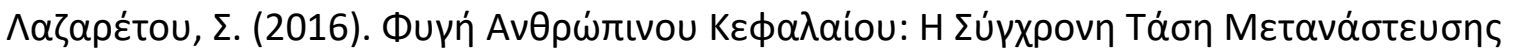

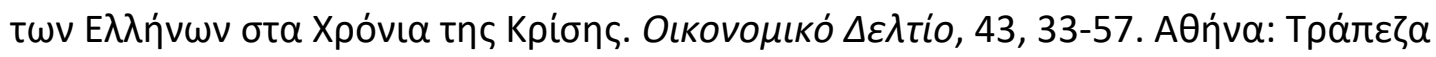

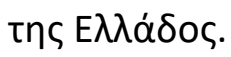




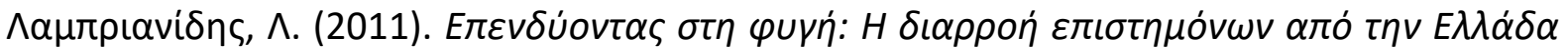

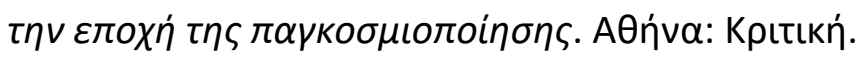

Leppänen, S., Westinen, E.,\& Kytölä, S. (eds.) (2017). Social media discourse, (dis)Identifications and diversities. London: Routledge.

Madianou, M., \& Miller, D. (2012). Migration and new media: Transnational families and polymedia. London: Routledge.

Seargeant, P., \& Tagg, C. (eds.) (2014). The language of social media: Identity and community on the internet. Basingstoke: Palgrave Macmillan.

Stamou, A. G. (2013). Adopting a Critical Discourse Analytical Approach to the Mediation of Sociolinguistic Reality in Mass Culture: The Case of Youth Language in Advertising. CriticalStudiesinMediaCommunication, 30(4), 327-346.

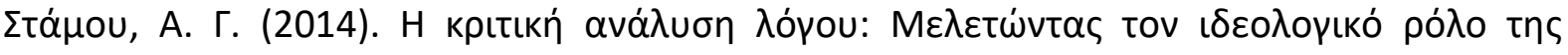

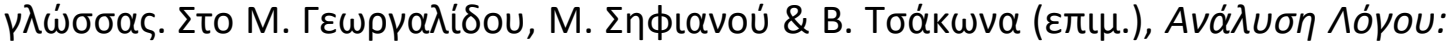

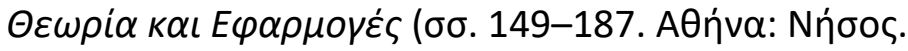




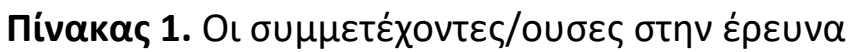

\begin{tabular}{|c|c|c|c|c|c|c|}
\hline 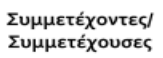 & 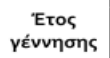 & 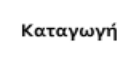 & 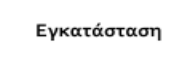 & 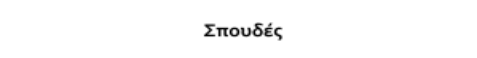 & 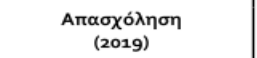 & Social media \\
\hline$\Delta \eta \mu \dot{r}^{\prime} \rho \eta \varsigma$ & 1980 & 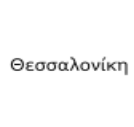 & 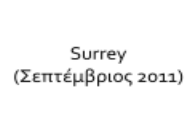 & 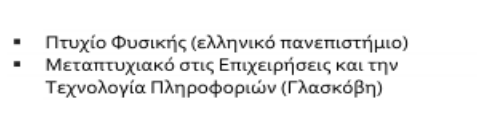 & $\begin{array}{c}\text { CRM Business Analyst } \\
\text { (Surrey) }\end{array}$ & $\begin{array}{c}\text { blog: } \\
\text { http://fromgruk.com/ } \\
\text { Facebook } \\
\text { Twitter } \\
\text { Instagram }\end{array}$ \\
\hline Avtwvia & 1990 & Tрік $\alpha \lambda \alpha$ & 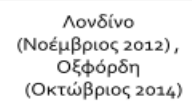 & 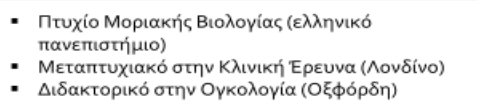 & 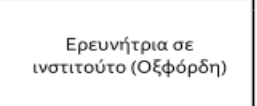 & $\begin{array}{l}\text { Facebook } \\
\text { Instagram }\end{array}$ \\
\hline$\Theta \alpha \dot{\lambda} \varepsilon_{1} \alpha$ & 1987 & 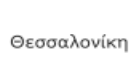 & 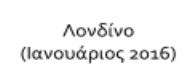 & 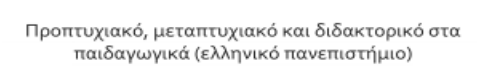 & 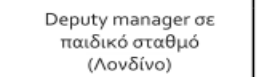 & $\begin{array}{l}\text { Facebook } \\
\text { Instagram }\end{array}$ \\
\hline Mixá̀n & 1991 & Xavió & 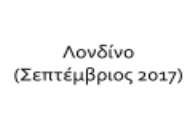 & 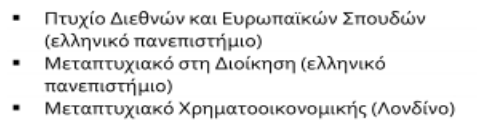 & 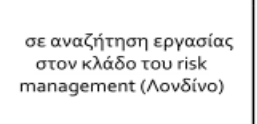 & $\begin{array}{l}\text { Facebook } \\
\text { Instagram }\end{array}$ \\
\hline$\sum \tau \dot{\varepsilon} \hat{\lambda \lambda \alpha}$ & 1986 & 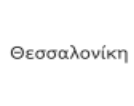 & $\begin{array}{l}\text { Bepo גivo } \\
\text { (aró to 2010) }\end{array}$ & 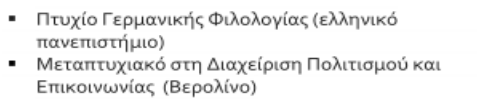 & 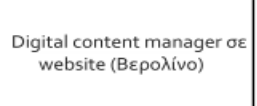 & Facebook \\
\hline Príyas & 1985 & 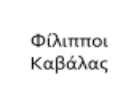 & $\begin{array}{c}\text { Móvo } \chi 0 \\
\text { (ató to 2012) }\end{array}$ & 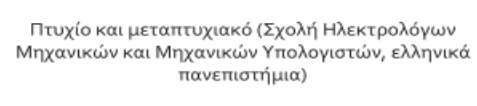 & 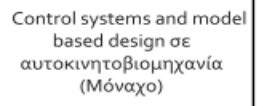 & $\begin{array}{l}\text { blog: http://imerologio- } \\
\frac{\text { ksenitemenou.blogspot }}{\text { coml }}\end{array}$ \\
\hline 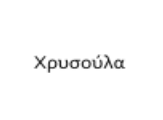 & 1980 & Aөńvo & $\begin{array}{c}\text { Móvoxoo } \\
\text { (aró Ampí̀ı 2013) }\end{array}$ & 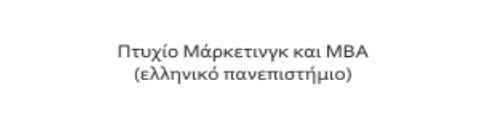 & 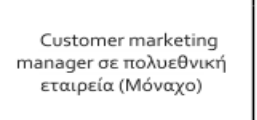 & $\begin{array}{c}\text { blog: } \\
\frac{\text { apomamasemama.com }}{(\sigma \varepsilon \lambda i \delta \alpha \text { blog } \sigma \varepsilon} \\
\text { Facebook kal } \\
\text { Instagram) }\end{array}$ \\
\hline
\end{tabular}

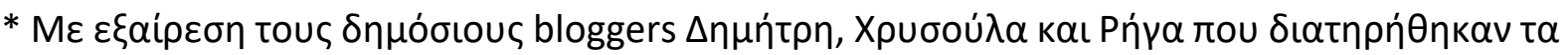

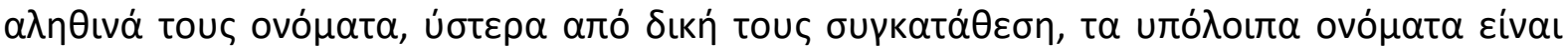
$\psi \varepsilon \cup \delta \omega \dot{v u \mu \alpha .}$ 